2006-01-01

\title{
Novel Gene Therapeutic Approaches to Brain Cancer
}

\author{
Maria Castro \\ Cedars-Sinai Medical Center \\ James Curtin \\ Technological University Dublin, james.curtin@tudublin.ie \\ Gwendalyn King \\ Cedars-Sinai Medical Center
}

See next page for additional authors

Follow this and additional works at: https://arrow.tudublin.ie/scschbiobk

Part of the Biochemistry, Biophysics, and Structural Biology Commons

\section{Recommended Citation}

Castro, M.G., Curtin, J.F. \& King, G.D., (2006). Novel Gene Therapeutic Approaches to Brain Cancer. Gene Therapy for Neurological Disorders, Chapter 13. (Taylor \& Francis Group). doi:10.21427/e3bq-qp57

This Book Chapter is brought to you for free and open access by the School of Biological Sciences at ARROW@TU Dublin. It has been accepted for inclusion in Books/Book chapters by an authorized administrator of ARROW@TU Dublin. For more information, please contact arrow.admin@tudublin.ie, aisling.coyne@tudublin.ie,gerard.connolly@tudublin.ie. Funder: National Institute of Health, Bram and Elaine Goldsmith Chair in Gene Therapeutics, The Linda Tallen and David Paul Kane Annual Fellowship, Board of Governors at Cedars Sinai Medical Center. 


\section{Authors}

Maria Castro, James Curtin, Gwendalyn King, Marianela Candolfi, Peter Czer, Sandra Sciascia, Kurt

Kroeger, Tamer Fakhouri, Sarah Honig, William Kuoy, Terry Kang, Stephen Johnson, and Pedro Lowenstein 


\title{
13
}

\section{Novel Gene Therapeutic Approaches to Brain Cancer}

\author{
Maria G. Castro, James F. Curtin, Gwendalyn D. King, Marianela Candolfi, \\ Peter Czer, Sandra A. Sciascia, Kurt Kroeger, Tamer Fakhouri, Sarah Honig, \\ William Kuoy, Terry Kang, Stephen Johnson, and Pedro R. Lowenstein \\ Gene Therapeutics Research Institute, Cedars-Sinai Medical Center, and Departments of \\ Medicine, and Medical and Molecular Pharmacology, David Geffen School of Medicine, \\ University of California Los Angeles, Los Angeles, California, U.S.A. \\ * Current Address: School of Biological Sciences, Dublin Institute of Technology, \\ Dublin 8, Ireland
}

\section{INTRODUCTION}

In the United States, approximately 17,000 people per year are diagnosed with brain tumors, the leading cause of death from cancers in children ages $1-15$ year $(1,2)$. Gliomas are the most prevalent type of brain tumors in adults, affecting 3.2/100,000 persons/yr in the United States (www.CBTRUS.org). In spite of advances in surgery, chemotherapy, and radiotherapy, the mean survival time of patients post-diagnosis remains approximately 9-12 months.

The nervous system is comprised of neurons supported and nourished by glial cells. There are four different types of glial cells: astrocytes, oligodendroctyes, microglia, and ependymal cells. Technically, a glioma is defined as "any neoplasm [an uncontrolled growth of abnormal tissue] derived from one of the various types of cells that form the interstitial tissue [glial cells] of the brain, spinal cord, pineal gland, posterior pituitary gland, and retina"(3), and they can also be found in nasal lobes, peripheral, and cranial nerves. In general, gliomas rarely metastasize beyond the central nervous system (CNS); however, tumors from other parts of the body can metastasize to the CNS. Gliomas may be found in many different regions of the CNS and are usually comprised of a heterogenous cellular population.

There are many different types of gliomas each with its own characteristic features. For example, there are brainstem gliomas, gigantocellular gliomas, mixed gliomas, nasal gliomas, gliomas of the optic chasm, optic nerve gliomas, gliomas of the spinal cord, telangiectactic gliomas (4). However, we will only discuss the main types: astrocytomas and mixed gliomas. Astrocytomas are located anywhere in the CNS, grow slowly, are invasive and are believed to originate from astrocytes. The most devastating type of astrocytoma, grade-four astrocytoma, is more commonly known as glioblastoma multiforme. It is located mostly in the cerebral hemisphere, is highly invasive, 
malignant, and probably originates from mature astrocytes. Glioblastomas are the most common type of brain tumors diagnosed in middle aged adults, accounting for about $30 \%$ of all primary brain tumors. They are the most malignant of all brain tumors and the most difficult to treat with mean survival of less than 1 year following diagnosis (4). Astrocytoma is also the most common pediatric tumor diagnosed, accounting for just over $50 \%$ of all newly diagnosed tumors in children (5). The diagnosis of gliomas includes recognition of its symptoms, performing physical tests and assigning a grade to the tumor. Symptoms of gliomas can include headaches (where pain increases especially when one lies down), nausea, vomiting seizures, dizziness, personality changes, sudden vision loss, memory loss, speech problems, sensory changes, mental impairment, weakness, and perhaps paralysis (6). A physician may utilize CT scans, MRIs, EEGs, $\mathrm{X}$-rays, angiography, myelography, and/or a lumbar puncture to diagnose gliomas. If a glioma is found, it is given a grade between one and four. A low grade glioma is a tumor with a well-defined border that grows slowly. A mid or high grade number is assigned to a tumor that grows more rapidly, is pathologically malignant and is difficult to remove due to invasion in normal tissue. High grade tumors typically recur within 1-2 year post treatment.

The current treatment for gliomas includes surgery, radiation, and chemotherapy. The first step in treatment for a glioma is resection or biopsy. With resection, as much of the tumor is removed as possible. A resection may also establish a pathological diagnosis as the results from a biopsy might not be conclusive. Unfortunately, the lack of a clearly defined tumor border makes it difficult to discern whether or not the entire tumor was removed by resection. Also, if the glioma is close to critical areas within the brain, there is a high risk of normal tissue damage during resections. In this case, partial resections can be of some value. A partial resection can improve neurological functions, relieve pressure, and increase tumor sensitivity to chemotherapeutic drugs. During surgery, shunts may also be placed near the tumor to relieve pressure and to drain excess fluid. A biopsy is useful when the tumor is inoperable and when imaging is difficult. Another therapeutic option is radiation therapy (maximum dose of $60 \mathrm{~Gy}$ ) which is typically confined to tumor mass and $2 \mathrm{~cm}$ of surrounding tissue. Hyperfractionated radiation is an exposure to more frequent fractions of a smaller dose of radiation over a smaller area of the brain. Stereotactic radiosurgery is an increased dose of radiation to tumors less than 1.5 inches in diameter that minimizes exposure of normal brain tissue by guiding the radiation with computer assisted imaging. In interstital radiation therapy (brachytherapy), radioactive pellets are implanted in tumor mass. Physicians also induce hyperthermia or use radiosensitizers, such as tirapazamine, to increase the response of a tumor to radiation. Chemotherapeutic drugs such as carmustine, lomustine, procarbazine, and vincristine are administered in six week cycles (6). The drawbacks of chemotherapy against brain tumors include the increase of chemoresistant cells, inadequate drug delivery and the problems posed by the bloodbrain barrier resulting in only limited success, with an $80 \%$ relapse in glioblastoma patients. In summary, current treatments for malignant or high-grade gliomas rarely achieve long-term tumor control with frequent recurrence of the tumor $(4,7)$ and death quite probable in the near future for those patients diagnosed with gliomas. Therefore, there is a critical need to develop novel therapeutic approaches to treat this devastating cancer. Gene therapy constitutes a very attractive treatment option and in this chapter will discuss some of the most promising gene therapeutic targets and precinical model systems. We will also review the clincal implementation of these therapies in GBM patients. 


\section{CANCER GENE THERAPY APPROACHES}

\section{Correcting the Primary Genetic Defect in Cancer Using Gene Therapy}

Cancerous cells usually harbor harmful mutations in genes that regulate proliferation and/or apoptosis. It is widely accepted that tumorigenesis is a multi-step process that requires mutations in many different genes in the DNA of an individual cell. Although the exact nature and order of these mutations varies between different types of cancer and even between cancers classified as the same type, a common theme is often evident during cancer progression. Mutations in genes that promote cell cycle progression, growth factor independence, angiogenesis, increased motility, anchorage independence, decreased levels of apoptosis and reduced sensitivity to chemotherapeutic agents are commonly reported in many different cancers and often correlate with progression of the cancer from benign to malignant. The genetics of gliomagenesis is well characterized in comparison with other cancers and this information can be used to develop gene therapy strategies that address these genetic aberrations. Mutations in four pathways involved in cell cycle regulation are commonly associated with glioma formation in humans; the p53/ARF/human MDM2 pathway, the pl6/Rb/cyclinD/CDK4 pathway, the receptor tyrosine kinase (RTK)/Ras pathway and the pI3K/PTEN/Akt pathway (8). Viral vectors have been designed that express transgenes commonly mutated in glioma in an attempt to correct the genetic lesions in gliomagenesis. Below we outline the progress in developing therapies for the two most commonly mutated pathways in glioma, p53, and Rb.

\section{P53/ARF/HumanMDM2 Pathway}

P53 is often referred to as "the guardian of the genome" and is mutated or absent in over $50 \%$ of all human tumors. The principle role of p53 as a tumor suppressor is to detect gross genetic abnormalities during DNA synthesis. Active p53 is absent in quiescent cells but its activation is induced in cells during cell cycle progression or in response to genotoxic insults. Once a genetic abnormality has been detected, p 53 arrests cell cycle progression and monitors the DNA repair process. If the DNA damage is too great, p53 activates the apoptotic pathway reducing the frequency of tumor formation. This pivotal role played by p53 in tumor suppression is perhaps most striking in humans with $\mathrm{Li}$-Fraumeni syndrome. Mutations in the p53 gene have been identified in over $70 \%$ of all these individuals and family members have an exceptionally high risk of developing multiple primary carcinomas and sarcomas during their lifetime (9). These patients are known to have a particularly high predisposition to developing glioblastoma and other tumors of the CNS (10). Other proteins known to regulate 553 expression and stability in cells include the transcription factor c-Jun, the ubiquitin-binding molecule MDM 2 and downstream effectors of $p 53$ including $\mathrm{p} 21$ and E2F1, all of which are frequently mutated in cancer as well. In fact, mutations in components of the p53 pathway are believed to occur in $>90 \%$ of all human tumors, including human gliomas. Allelic loss of chromosome $17 \mathrm{p}$ or mutations in p53 gene are observed with equal frequency in low grade gliomas and high grade glioblastomas (11). This suggests that inactivation of $\mathrm{p} 53$ is an early event during gliomagenesis and may be an important target for gene therapy. Re-introduction of wild-type p53 into glioma cells with p53 mutations has been the subject of intense scientific research. Early results suggested that the re-introduction of p53 reduced the proliferation of glioma cells in vitro and suppressed tumor formation when implanted into nude mice (12). Adenovirus with the p53 transgene was subsequently demonstrated to reduce tumor volume by $40 \%$ over 14 days in rats, demonstrating significant anti-tumor activity $(13,14)$. p53 is known to regulate cell cycle progression, but mutations in p53 are also associated with a variety of other functions 
including multi-drug resistant cancer cells. P53 overexpression increased the sensitivity of drug and radiation resistant glioma cell lines to cisplatin and radiotherapy in vitro (15) and adenovirus expressing p53 restored the sensitivity of 9L glioblastoma cells to cisplatin (16) and radiotherapy (17) in a rat model of glioblastoma. Overexpression of p53 using viral vectors was also observed to improve survival in animal models inoculated with wild type p53 expressing glioma cell lines, indicating a versatile function for this transgene in treating all forms of glioma (18). Overexpression of p53 in cells increases the expression of numerous apoptotic proteins including BAX activators, Bim, DP5, and the death receptor ligand FasL. In a recent study, adenoviral vectors expressing p53 under the control of the CMV promoter were demonstrated to induce significant levels of apoptosis as measured by DNA fragmentation when injected intracranially into the tumor. Furthermore, a $100 \%$ survival rate was observed in these animals 100 days following viral injection (19). The success of these pre-clinical studies has led to Phase I clinical trials designed to assess the toxicity of p53 gene therapy in human patients. The results of one trial have been recently published to show the maximum tolerated dose was not reached and transgene expression was evident in all patients in the nucleus of astrocytic tumor cells. Although expression was limited to within $5 \mathrm{~mm}$ from the site of injection, it is hoped that higher doses of virus may improve the distribution in subsequent studies (20).

A number of downstream pathways of p53 have also been tested and the overexpression of two of these have shown promising results in controlling glioma in preclinical animal models $(21,22)$. Comparison between $\mathrm{p} 53$, p21, and p16-based therapies suggests that vectors expressing p16 and p21 are even more potent tumor suppressors than p53 (23). However, these transgenes have not yet been tested in clinical models of glioma.

An alternative strategy was originally conceived by Bischoff JR and others, which takes advantage of the anti-viral properties of p53. The human AdE1B gene is expressed during adenovirus infection and codes for a $55 \mathrm{kDa}$ protein that binds with and inactivates p53. AdE1B is essential for a successful replication cycle within the host cell and adenoviral vectors lacking the AdE1B gene are unable to replicate inside cells expressing normal p53. These recombinant viral particles were cytopathic against p53-deficient human tumor cell lines both in vitro and also in flank tumors in nude mice. Furthermore, these viruses increased the efficacy of other viral vector therapies expressing cytotoxic transgene products $(24,25)$. In a recent report, combined therapy using this virus and conventional radiotherapy was significantly more effective than either therapy alone in improving the long term survival of nude mice with both $\mathrm{p} 53$ positive and $\mathrm{p} 53$ negative glioma (26). These results highlight a common trend with viral vectors as useful therapies when combined with more conventional chemotherapy or radiotherapy.

\section{P16/Rb/CyclinD/CDK4 Pathway}

The $\mathrm{p} 16 / \mathrm{Rb} / \mathrm{cyclinD} / \mathrm{CDK} 4$ pathway is the most frequently mutated pathway in glioma, and its mutations generally characterize a transition from low-grade tumors with relatively slow rate of proliferation to intermediate-grade gliomas with dramatically increased cell proliferation (27). In normal quiescent cells, $\mathbf{R b}$ is present in a hypophosphorylated form and is bound by the transcription factor E2F1. This prevents transcription of genes important for mitosis and prevents progression of the cell cycle through the G1/S phase restriction point (28). In general, mutations targeting the $\mathrm{Rb}$ pathway often inactivate $\mathrm{Rb}$ directly through decreased affinity for E2F1 or reduced expression. Alternatively, mutations that induce constitutive phosphorylation of $\mathrm{Rb}$ by CDK2, CDK4 or CDK6 can all contribute to reducing the affinity of $\mathrm{Rb}$ for $\mathrm{E} 2 \mathrm{~F} 1$ and subsequent increases in proliferation (28). In gliomagenesis, allelic losses on chromosome $9 q$ or $13 q$, or 
amplification of $12 \mathrm{q}$ usually accompany transition of glioma from low grade to intermediate grade $(29,30)$. This was later found to correspond with loss of $\mathrm{Rb}(13 \mathrm{q} 14)$ loss of INK4A and ARF (9p21), or amplification of CDK4 (12q13-14). Adenovirus mediated $\mathrm{Rb}$ gene therapy has been successfully used in pre-clinical models of various cancers including bladder cancer, where constitutively active truncated $\mathbf{R b}$ delivered by adenovirus produced marked growth inhibition, cytotoxicity, caspase-dependent apoptosis, and G2/M block in the human RB-negative, telomerase-positive bladder cancer cell line UM-UC14 (31). In an animal model, Rb was found to decrease the proliferation of spontaneous pituitary tumors in $\mathrm{Rb}^{+/}$mice and prolonged survival of animals (32). In a similar strategy to the oncolytic virus targeting p53, recombinant adenovirus lacking AdE1A (Delta24) can only replicate in cells expressing phospho-RB and is preferentially cytotoxic to glioma cells. A single injection of Delta24 reduced growth of flank tumors by $66 \%$, and multiple injections reduced tumor growth by $84 \%$ (33). These data clearly highlight the fundamental role played by $\mathrm{Rb}$ in pathogenesis of glioma.

More recently, substantial research has also investigated the potential of $\mathrm{Rb}$ regulators and effectors in treating glioma. In particular, therapies that target $\mathrm{p} 16^{\text {INK4A }}$ have successfully reduced tumor proliferation and improved survival in rodent models of glioma. $P 16^{\mathrm{INK} 4 \mathrm{~A}}$ reduces $\mathrm{Rb}$ phosphorylation by inhibiting CDK 4 and CDK6 activity and is the most frequently mutated gene in human cancer after p53 and is mutated in more than $50 \%$ of glioblastomas (34). Initial in vitro experiments demonstrated that adenoviral vectors expressing $\mathrm{p} 16^{\mathrm{INK} 4 \mathrm{~A}}$ induced cell cycle arrest of glioma cell lines (35). Results in vivo corroborated these initial observations and $\mathrm{p} 16^{\mathrm{INK} 4 \mathrm{~A}}$ delivery was demonstrated to improve survival in animal models of glioma, even when compared with p53 expressing vectors (23).

In spite of these promising results, caution is warranted with all therapies designed to repair common genetic lesions in glioma. In a recent report, $\mathrm{p} 16^{\mathrm{INK} 4 \mathrm{~A}}$ was expressed in glioma cell lines under the control of the Tet repressor system (36). Elevated p16 ${ }^{\text {INK4A }}$ reduced tumor proliferation in vivo initially, supporting work published by others (36). However, long term transgene expression induced a decrease in the expression of $\mathrm{Rb}$ suggesting that gene therapy approaches involving $\mathrm{p} 16^{\mathrm{INK} 4 \mathrm{~A}}$ may ultimately lead to the selection of Rb deficient tumors (36). In fact, this is a potential problem of all approaches designed to correct genetic lesions in cancer. Tumor cells are genetically unstable and undergo accelerating genetic mutation. Unfortunately, this accelerates natural selection and will select for tumor cells that overcome this transgene insertion. The possibility of tumor cells compensating for transgene insertion through one or more subsequent mutations must be explored in all promising therapies that repair the primary genetic lesion in cancer.

\section{Suppressing Angiogenesis}

Microscopic tumors are composed of populations of cells with altered characteristics to the surrounding tissue that contribute to growth factor independence and elevated rates of proliferation. In tumors, the rate of proliferation exceeds the rate of cell death and tumors increase in size. Oxygen and nutrients required to fuel this expansion in tumor volume are scavenged from surrounding tissue vasculature. However, diffusion of oxygen and nutrients from neovascularure limits the absolute size of the tumor to about $2 \mathrm{~mm}^{3}$. Angiogenesis is required to supply sufficient oxygen and nutrients to sustain further growth. Angiogenesis involves the rapid proliferation of endothelial vascular cells and is tightly regulated in adults. This regulation is coordinated by the expression of activators 
and inhibitors of angiogenesis. Tumors that acquire the ability to alter the expression of promoters or inhibitors of angiogenesis stimulate the development of new vasculature and subsequently increase in size. In fact, promotion of angiogenesis appears to be a critical step in the progression of glioma from a benign, microscopic lesion to a malignant macroscopic cancer (37). Consequently, angiogenesis has received much attention as a target of potential therapies. Angiogenesis in adult humans usually only occurs in response to pathophysiological stimuli from wounds or hypoxia and angiogenic inhibitors generally have few side effects (38). Several of these angiogenic inhibitors have been shown to reduce tumor growth in vitro and in vivo and of these, thalidomide has been most successfully used to treat glioma to date (39-42). However, a number of disadvantages limit the potential of angiogenic inhibitors in clinical setting. Firstly, production of sufficient quantities of angiogenic inhibitors is problematic and has limited the availability of these drugs in clinical trials. Synthetic small molecule inhibitors of angiogenesis are being developed to overcome this problem but the side effects of these drugs are currently unknown. Secondly, angiogenic inhibitors are believed to be cytostatic, not cytotoxic and this requires long-term treatment strategies to control and ultimately reduce tumor size. Thirdly, toxic side effects have been observed with systemic delivery of some angiogenic inhibitors (43). Gene therapy offers distinct advantages over conventional chemotherapy in the safe delivery of clinically effective doses of angiogenic inhibitors to the tumor and has been successfully employed in the treatment of a variety of tumors in preclinical studies (44). This section will explore the various strategies employed by gene therapy in treating brain tumors targeting both promoters and inhibitors of angiogenesis.

\section{Promoters of Angiogenesis}

The first growth factor identified as a positive regulator of angiogenesis was basic fibroblast growth factor (bFGF) (45). Glioblastoma is among the most highly vascularized of all tumors and increased expression of bFGF correlates with progression of a wide variety of solid tumors (46). Adenoviral gene transfer of bFGF was found to promote angiogenesis in rat brains (47). However, a clear correlation between increased bFGF expression and glioma progression has not been demonstrated in glioma suggesting that bFGF is not the principle mediator of angiogenesis (48). Another promoter of angiogenesis called vascular endothelial growth factor (VEGF) was found to be overexpressed in high grade gliomas (49). Expression of the receptors for VEGF, Flt-1 (VEGFR-1) and Flk-1 (VEGFR-2), are also elevated in glioblastoma in comparison with surrounding normal tissue and Flk-1 in particular is believed to promote angiogenesis in response to VEGF (50). VEGF was one of the first proteins identified to play a key role in angiogenesis $(51,52)$ and has since been the target of numerous gene therapy strategies designed to reduce tumor burden. Early studies utilized anti-sense RNA to reduce expression of VEGF in tumor cells. It was found that transfection of anti-sense VEGF cDNA into rat glioma C6 cells in vitro impaired C6 tumor cells growth in vivo when implanted into nude mice (53). More recently, recombinant virus has been used as a vehicle for the transfer of antisense sequences in pre-clinical models of brain tumors. Retrovirus encoding antisense VEGF cDNA sequence showed a statistically significant improvement in survival of rats with intracranial neoplasms (54). An alternative strategy for interfering with VEGF function has also been explored. A VEGF-R2 mutant has been constructed that lacks normal kinase activity. This receptor displays dominant negative function when overexpressed in cells that also express the wild type VEGF-R2 and a retrovirus encoding this mutant VEGF2 receptor successfully prolonged survival of rats 
with intracranial tumors. These tumors displayed many classical signs of impaired angiogenesis including reduced vascular density and elevated necrosis (55).

\section{Inhibitors of Angiogenesis}

The relatively low percentage of cells transduced by recombinant viral vectors is a limiting factor in reducing promoters of angiogenesis, and indeed in every gene therapy strategy that aims to reduce the expression or activity of target proteins. Inhibitors of angiogenesis overcome this problem and have been the subject of numerous pre-clinical studies. Many naturally occurring inhibitors of angiogenesis are derived from proteolytic degradation of the extracellular matrix. Endostatin and angiostatin are generated following the proteolytic cleavage of plasminogen and collagen respectively and are potent inhibitors of angiogenesis $(56,57)$. These peptides are difficult to generate in sufficient quantities in vitro and are ideal candidates as transgenes for gene therapy. Recombinant viral vectors that express endostatin $(58,59)$ or angiostatin $(60,61)$ have been developed and tested in preclinical models of glioma. Improved survival of animals with intracranial neoplasms was observed in all cases and tumor growth rates were reduced by as much as $90 \%$. Other anti-angiogenic protein fragments have also been studied for effectiveness in animal models of glioma and these include soluble human platelet factor four and the $\mathrm{N}$-terminal fragment of rat prolactin. However, it appears that these transgenes are not as effective as endostatin and angiostatin in significantly improving survival $(62,63)$. A number of proteins associated with immune system function have also anti-angiogenic properties. IL-4 and Interferon gamma have been studied in rat models of glioma $(64,65)$. Improved survival and reduced angiogenesis and tumor growth rates were also observed in these studies. However, the principle function of these transgenes is in recruiting and modulating various cellular and humoral aspects of the immune response and will be dealt with in the appropriate section.

\section{Activating the Immune Response}

Histological analysis of tumors reveals that an immune response is often elicited against the tumor. Inflammation, and even tumor-specific lymphocytes are often evident, and in some rare cases, tumor regression spontaneously occurs in response to autoimmune paraneoplastic syndromes $(66,67)$. This is believed to be caused by tumor specific antigen expression and underscores a role for the immune system in cancer immunosurveillance and control of disease. Unfortunately, most tumors develop countermeasures that hamper an effective immune response developing against the growing tumor. In pancreatic $\beta$-cell tumors for example, it has been demonstrated that the immune system was incapable of either developing or maintaining an effective anti-immune response $(68,69)$. More recent studies in sarcoma suggest that tumor antigens fail to reach the lymph nodes and consequently an effective cytotoxic $T$ lymphocyte response is not evident (70). Consequently, there is significant interest in developing an immunotherapy to improve the response of the immune system to the tumor. Since the immunosuppression state associated with gliomas appears to be mediated by an increase in autocrine secretion of transforming growth factor-beta (TGF-beta), a TGF-beta inhibitor, decorin has been delivered to intracranial CNS-1 gliomas in vivo using adenoviral vectors, which prolonged the survival of experimental tumor bearing rats, slowing glioma progression (71). Recent progress in understanding the mechanisms of an immune response has led to a renaissance in immunotherapy and over 100 Phase II clinical trials studying the effectiveness of various cancer vaccines are currently underway in the United States. 
Many of these are already showing promising results with minor, limited side effects (73). Gene therapy offers numerous different mechanisms to stimulate an immune response against the proliferating tumor. We shall briefly outline progress in the four most promising mechanisms below.

\section{Tumor Antigen Delivered Through Adenoviral Transgene Expression}

Most if not all tumors express proteins that are recognized by the immune system and are called tumor antigens. Adenoviral vectors can be engineered to express these antigens as transgenes and subsequently used to prime an immune response against that target antigen if injected systemically. Promising results from preclinical trials have been reported for renal cell carcinoma among others, where adenovirus expresses the tumor antigen carbonic anhydrase IX protein (73). However, it is unclear whether this approach would be effective reducing glioma in an immune-privileged organ as the brain.

\section{Enhancement of the Anti-Tumor Immune Response Using Cytokines}

Cytokines are a diverse collection of secreted and membrane bound proteins involved in immunity and inflammation. Interferon $\beta$, an immunomodulatory and anti-tumor cytokine has been demonstrated to provide systemic anti-tumor immunity against GL261 cells when delivered intracranially in lysosomes. This cytokine reduces tumor growth and improves survival in C57/BL6 mice through a combination of anti-proliferative effects and also activation of $\mathrm{CD} 8^{+}$but not $\mathrm{CD} 4^{+}$cells (74). In another report, tumor growth was suppressed when mice were treated with a combination of IFN- $\beta$ gene via cationic liposomes and dendritic cells. This was mediated by a highly effective cytotoxic lymphocyte (CTL) response against the tumor and was far more efficient that either therapy alone (75). Adeno-associated virus designed to deliver the transgene IFN $\beta$ has also been developed and completely inhibits growth of exogenous human tumor xenografts when delivered intratumorally in nude mice, further supporting the potential of IFN- $\beta$ as a novel therapy for treating human glioma (76). Phase I clinical trials have recently begun using a replication deficient adenovirus expressing IFN- $\beta$ in human subjects with the primary aim of assessing the maximum tolerated dose (77).

\section{Enhancing T-Cell Activation}

A number of cytokines are believed to activate various subclasses of $\mathrm{T}$ lymphocytes. For example, $I L-12$ is required for anti-tumor $T_{H 1}$ type pattern of differentiation in naïve mature $\mathrm{T}$ lymphocytes. An adenovirus expressing the transgene $\mathrm{IL}-12$ has been reported to enhance the immune response against brain tumors and improve survival in mice inoculated with GL26 glioma cells intracranially. At the tumor site an increased number of $\mathrm{CD}^{+}$and $\mathrm{CD}^{+} \mathrm{T}$ cells were identified (78). Recently, allogenic cells genetically engineered to secrete $\mathrm{IL}-2$ were found to significantly improve survival in a mouse glioma carcinoma model. The immune response was found to be predominantly mediated by $\mathrm{CD} 8^{+}$and natural killer cells (NK) and was highly specific for the glioma cells above nonneoplastic cells (79).

\section{Enhancing Dendritic Cells Activation}

It is believed that dendritic cells are the principle antigen presenting cells of the immune system and are required for the development of an antigen-dependent immune response. However, dendritic cells are absent from the brain except under conditions of inflammation and it is believed that this is a major reason behind immune privilege in 
the brain (80-85). Dendritic cells differentiate from precursor cells in response to Fit3L through a STAT3 dependent mechanism (86). Expression of Flt3L by daily administration of purified, recombinant Flt3L has been demonstrated to induce complete tumor regression and significantly improve survival (87). Furthermore, dendritic cells are highly effective inducers of tumor specific killer and helper $\mathrm{T}$ lymphocyte generation in animal models of tumors (88). Therefore, a lot of interest has been generated recently surrounding the use of dendritic cells and Flt3L in immunotherapy. The use of dendritic cell based vaccines is currently ongoing in about 20 Phase II and at least one Phase III clinical trial in the U.S.A., many of which are showing promising results. In addition, early studies have indicated that toxicity of dendritic cell vaccination is mild and limited to local reactions at the site of injection (72). In a stringent glioma model, in which RAdTK/ganciclovir administration is ineffective, we have demonstrated that recombinant adenovirus expressing RAdFlt3L eliminates intracranial neoplasms and significantly improves survival when co-delivered with the tumoricidal agent RAdTK/ganciclovir $(89,90)$. This data highlight the promise of immunotherapies in greatly enhancing the efficacy of current therapies and the potential of curing glioma.

\section{Harnessing Death Receptor Ligand Interactions}

Apoptosis, also known as programmed cell death, is a universal feature of multi-cellular eukaryotes and plays a fundamental role in controlling many diverse physiological processes including tissue sculpting during development and tissue homeostasis in adults. Defects in apoptosis are responsible for numerous pathologies including tumor initiation and progression $(91,92)$. For these reasons, apoptosis is tightly regulated and studies in vertebrates have identified a number of signal transduction pathways that can either induce or inhibit apoptosis. A number of studies have investigated the potential selectively activate tumor cell death by inducing pro-apototic genes using gene therapy (93). In particular, focus has centered on components of a family of receptors called death receptors.

Death receptors are present on the plasma membrane and their activation can induce apoptosis in cells following engagement of receptors with extracellular ligands. In mammals, death receptors belong to a large family of membrane bound receptors called the tumor necrosis factor receptor superfamily (TNFRSF), which include at least nine death receptors. TNFRSF members regulate various aspects of cell proliferation, differentiation, and apoptosis and all members of this family contain between one and four short cysteine-rich extracellular domains. These repeats usually contain six conserved cysteine residues that form three disulphide bonds and these subdomains adopt conserved tertiary folds. It is believed that the order of cysteine rich repeats determines the affinity and specificity of receptor for ligand. The ligands that bind with these receptors belong to another large family of transmembrane proteins called the tumor necrosis factor superfamily. Ligands bind with receptors and induce trimerisation of receptors at the plasma membrane, which in turn permits the recruitment of initiator caspases to the death domain, propagating the apoptosis inducing signal transduction cascades $(94,95)$. Initiator procaspases cleave effector caspase which, once activated, inactivate target proteins and thereby promoting the ordered degradation of nucleic acids, enzymes, and structural proteins (96).

The Fas receptor is perhaps the most widely studied death receptor and ligand system. Viral vectors expressing Fas ligand have been demonstrated to possess potent antiglioma activity both in vitro and in vivo (97-99). Furthermore, these vectors enhance the anti-tumor activity of virus expressing p53 and Thymidine kinase (TK) $(100,101)$. TRAIL, 
the ligand for TRAILR1 and TRAILR2, has also been assessed as a potential therapeutic transgene for gene therapy. The anti-tumor activity of recombinant virus expressing TRAIL is more controversial, although this transgene is not effective alone in glioma cell lines (102), co-delivery of TRAIL and Fas ligand expressing viral vectors enhances apoptosis induction compared to either virus alone (103). In addition, intracranial injection of virus expressing TRAIL significantly improves survival in a rat model of glioma (104).

\section{Providing Drug Resistance to Hematopoietic Cells}

Gene therapy vectors can not only be used to kill tumoral cells, but also be engineered to confer survival advantages on normal cells. A limiting factor with conventional radiotherapy and chemotherapy is the toxicity to normal cells. Many of these therapies are toxic to proliferating cells, including but not limited to tumor cells, and relatively non-toxic to non-proliferating cells. Although the majority of cells in adults are non-proliferating, a small but important proportion of these are rapidly dividing. Hematopoietic stem cells are rapidly dividing cells that are often decimated in response to radiotherapy and chemotherapy. Bone marrow transplants are often required, increasing the risk of anemia, infection, and further complications in cancer patients. Stem cells can be transduced in vitro where drug resistant stem cells can be selected and amplified in vivo (105). A number of Phase I clinical trials have been undertaken with various chemotherapy drug resistant genes including 0-6-methylguanine-DNA methyltransferase gene and MDR-1 (106). Although many of these approaches have not been very successful, in part due to poor transduction efficiencies, recent improvements in vector design may increase the efficacy of these agents in promoting drug resistance in vivo (107). Many of these vectors are retroviral in origin and may result in the accidental transfer of the drug resistance gene to cancer cells via retroviral integration into cancer genomes. Therefore safety checks including replication deficiency and inefficient repackaging of the multi-drug resistance gene are also being developed in these vectors.

\section{Enzyme/Prodrug Gene Therapy}

While radiotherapy and surgery succeed in treating confined malignancies, the majority of cancers require systemic therapies that target tumor cells but, unfortunately their low specificity also produces toxicity to normal cells. Current research is attempting to identify more specific ways to directly target tumor cells and reduce treatment toxicity to normal cells. The use of enzyme/prodrug combinations directly targeting therapeutics to the tumor mass through the use of antibody or viral vectors has emerged as a potentially viable option.

Prodrugs are chemicals that are non-cytotoxic over a wide range of dosages however upon conversion by a specific activating enzyme, become a toxic molecule capable of triggering cell death. The ideal prodrug should (1) be freely diffusible throughout the tumor (2) remain chemically stable under physiological conditions, (3) possess suitable pharmacological and pharmacokinetic properties, (4) convert into a chemical that is at least 100 -fold more toxic than the prodrug, and (5) induce cytotoxicity that is cell cycle phase independent. In addition to the prodrug characteristics, dynamics of the enzyme are also crucial to successful cancer treatment. Ideal enzymes should be of low molecular weight with high catalytic activity under physiological conditions such that even at low concentrations of prodrug, efficient catalysis can occur. Expression of the enzyme should not alone lead to cytotoxicity. Additionally the reaction pathway for conversion of the prodrug into a toxin should be unique from pathways utilized by endogenous enzymes to avoid cytotoxcicity in normal tissue (108). 
Initial investigations sought to exploit prodrug activation using endogenous enzymes expressed at higher levels in tumor cells $(109,110)$. However, clinical application was limited since such enzymes were expressed in normal cells and only a small number of human cancers had high enough levels of activating enzymes for efficacy. To overcome these problems, identification of non-mammalian enzyme/prodrug combinations were identified. Usage of antibodies and viral vectors to specifically target enzyme to tumor tissue has produced promising results in vitro and in vivo.

\section{Antibody-Directed Enzyme Prodrug Therapy}

Antibodies have been used to target tumor antigens or growth factors in attempts to specifically deliver cytotoxic drugs, toxins, and radionucleotides $(111,112)$. Likewise conjugation of prodrugs to monoclonal antibodies may also be used for specific targeting (113-115). In antibody-directed enzyme prodrug therapy (ADEPT); the catalytic enzyme is covalently linked to an antibody, which recognizes tumor-specific antigen and binds to this specific surface antigen, causing its internalization together with the activating enzyme. Upon prodrug administration a large number of toxic molecules can be produced in the local tumor area. Since internalization of the complex is not required for catalysis, diffusion of the toxin into nearby tumor cells may result in tumor cell death. Likewise, transfer of toxin after its internalization to adjacent cells via gap junctions further enhances the bystander effect of ADEPT. In order to minimize death of normal cells, administration of the enzyme used to convert the prodrug can be time delayed to allow removal of unbound enzyme-antibody conjugates.

There are several disadvantages to ADEPT that limit its clinical applications. One limitation is the low number of tumor-specific antigens that have been identified thus far for use as targets; however ADEPT strategies have been used to treat colorectal, breast, and choriocarcinoma tumors. In addition, most monoclonal antibodies are of murine origin and elicit a significant immunogenic response in a human patient that requires use of immunosuppressive drugs. Humanized antibodies have been constructed that retain the mouse antibody determining region and its high affinity binding but within a human antibody framework (116-118). Last, monoclonal antibodies are large molecular weight molecules with slow rates of diffusion that may limit the total tumor area able to be treated $(119,120)$. Use of recombinant antibodies engineered to be smaller while retaining a high specificity and affinity may overcome this limitation (121-126).

\section{Gene-Directed and Virus-Directed Enzyme Prodrug Therapy}

To further extend ADEPT while overcoming some of its limitations, utilization of vectors other than monoclonal antibodies were developed. Gene-directed enzyme prodrug therapy (GDEPT) seeks to introduce a gene encoding a prodrug-activating enzyme directly into tumor cells. Once inside the cell transcription of the gene produces an active but noncytotoxic enzyme. Upon systemic administration of the prodrug, cells transduced with the enzyme will convert the prodrug into its toxic metabolite triggering cell death. For GDEPT to be successful the enzyme must be expressed exclusively within the tumor cells and its catalytic activity must be high enough compared to normal tissue for clinical benefit. Since expression will not occur in all tumor cells, a significant bystander effect is essential in this strategy. Bystander effects occur when the cytotoxic metabolite is transmitted to cells not originally transduced with the enzyme. This may occur via transport through gap junctions or by diffusion through the extracellular space. In addition to delivery of the enzyme, administration of the prodrug must be delayed sufficiently to allow expression of the 
enzyme in target cells. The majority of GDEPT strategies have exploited viral-mediated delivery systems. These systems exploit the ability of viruses to enter cells and express the transgenes they carry. Use of viruses as the delivery agent has been termed virus directed enzyme prodrug therapy or VDEPT.

\section{Enzyme/Prodrug Combinations}

A large number of enzyme/prodrug combinations have been discovered and characterized. While the ideal characteristics for enzymes and prodrugs used in ADEPT/GDEPT strategies was outlined above, none of the enzyme/prodrug combinations are perfect, each has its advantages and disadvantages. The most well characterized enzyme/prodrug combinations are herpes simplex virus type 1 - thymidine kinase (HSV1-TK)/ganciclovir $(\mathrm{GCV})$ and cytosine deaminase (CD)/ 5-fluorocytosine (5-FC). Each of these pairings has been used in numerous gene therapy GDEPT clinical trials. The bacterial enzyme carboxypeptidase G2 (CPG2)/CMDA is the only ADEPT combination to reach clinical trial stage. In addition to these well characterized pairings $E$. coli guanine phosphoribosyl transferase/6-thioxanthine, cytochrome P450/CPA, E. coli purine nucleoside phosphorylase/6-methyl-purine-2'-deoxynucleoside, E. coli nitroreductase/CB1954, cytochrome P450 4B1/4-IM and 2AA, horseradish peroxidase/indole-3-acetic acid and carboxypeptidase/methotrexate- $\alpha$-phenylalanine have all been under investigation $(108,127)$.

\section{Herpes Simplex Virus Type 1: Thymidine Kinase/Ganciclovir}

HSV1-TK was first developed as a prodrug-activating enzyme by Moolten and has been studied intensively in preclinical and clinical studies to treat a wide range of solid tumors $(128,129)$. HSV1-TK delivery to tumor cells has been accomplished using both adenoand retroviral vector systems (130-137). HSV1-TK is nearly 1000 -fold more efficient at mono-phosphorylation of GCV than any mammalian HSV1-TK (138). GCV, acyclic analog of the nucleoside 2-deoxyguanosine, is an anti-herpetic agent with a known toxicity profile (138-141). When HSV1-TK phosphorylates GCV it is converted to GCV-monophosphate that is further converted by other cellular kinases to di- and triphosphorylated forms. GCV-triphosphate is the most toxic of these forms (138-141). GCV-triphosphate is structurally similar to 2-deoxyguanosine triphosphate and thus can be incorporated into DNA chains by DNA polymerase (138-141). GCV-triphosphate may inhibit DNA polymerase or upon incorporation into the DNA chain, trigger chain termination which induces cell death (139-141).

HSV1-TK/GCV pairing was the first in which bystander effects were described (142). In murine glioma studies, total tumor regression was observed when only $10 \%$ of tumor cells were transduced with HSV1-TK $(130,142,143)$. HSV1-TK/GCVs bystander effect requires cell to cell contact. GCV-triphosphates are highly charged molecules that are insoluble in lipid membranes and thus cannot diffuse freely in the extracellular space. Instead, GCV-triphosphates move between cells via gap junctions (144-147). In addition to movement through gap junctions the bystander effect of HSV1-TK/GCV may be enhanced by the host immune response to the tumor following treatment. Treatment was observed to trigger infiltration of CD4 + and CD8 + T cells and macrophages as well as increased expression of a host of cytokines (148). Induction of the immune system resulted in tumor regression locally at the site of HSV1-TK/GCV action and at distant sites in both normal and immunocompromised animals (136,149-151). 
Based on positive preclinical tumor regression data, HSV1-TK/GCV studies have been conducted as Phase I and Phase II clinical trials. In the initials trials undertaken, survival of patients treated with HSV1-TK/GCV after surgical resection were similar to patients who had not received the GDEPT therapy $(152,153)$. Several theories exist for the disparity between preclinical and clinical trial data. First, an insufficient number of tumor cells may have been transduced for therapeutic benefit. Second, the growth rate of the tumor cells may play an important role in HSV1-TK/GCV action and would be different between experimental tumors and those spontaneously arising in humans. Third, the dosages of GCV used preclinically were much higher than those used in the clinical trials indicating that the lack of GCV substrate may have precluded therapeutic benefit. Increased tumor transduction efficiency, exploitation of bystander effects, and further engineering of HSV1-TK to be more efficient and/or GCV to be less toxic will be required for clinically relevant therapeutic benefits from HSV1-TK/GCV prodrug therapy.

\section{Cytosine Deaminase/5-Fluorocytosine}

As with HSV1-TK, CD produces a toxic nucleotide analog that triggers cell death. CD is an enzyme expressed in bacteria and fungi and absent in in mammalian cells catalyzes the conversion of cytosine to uracil $(154,155)$. When combined with the prodrug 5-FC, deamination generates 5-fluorouracil (5-FU). CD/5-FD kills cells via both proliferation-dependent and independent means. Metabolites of 5-FU cause cell death through inhibition of thymidylate synthase, resulting in nicked DNA and inhibition of RNA processing. CD/5-FC results in a strong bystander effect that, unlike HSV1-TK/ $\mathrm{GCV}$, does not require cell to cell contact (156). Transduction of only $2-4 \%$ of cells resulted in significant regression of tumor as toxic metabolites freely diffuse cells $(157,158)$. This effect is not restricted to tumor cells and damage to normal tissue may result. In addition to bystander effects caused by diffusion of the toxin, as with HSV1TK, immune mediated bystander effects also occur as NK infiltrate tumors treated with $\mathrm{CD} / 5$-FC therapy (159). The species of origin for CD may produce more catalytically active forms as observed with $S$. cerevisiae CD compared to $E$. coli $C D(160,161)$. Currently Phase I trials of adenovirally delivered $C D$ in patients with metastatic liver disease are ongoing (162-164).

\section{Carboxypeptidase G2/4-Benzoyl-L-Glutamic Acid}

CPG2 is found in bacteria but not humans and removes glutamic acid moieties from folic acid, inhibiting cell growth. When combined with the prodrug 4-benzoyl-Lglutamic acid (CMDA), a DNA-crosslinking mustard drug is released (165). Unlike HSV1-TK and CD, catalysis of the prodrug with CPG2 does not require further enzymatic processing to become the final toxic compound. Mustard-alkylating agents are not cell-cycle dependent enabling the killing of proliferating and non-proliferating cells (166). As with other enzyme/prodrugs, CPG2/CMDA produces a robust bystander effect. Only $10-12 \%$ transduction resulted in $50-100 \%$ killing in vitro and in vivo (167-169). Immune mediated bystander effects are currently unreported. CPG2/CMDA was first used in ADEPT Phase I clinical trial and did not show toxicity related to the enzyme or prodrug $(162,163)$. GDEPT usages of CPG2 have not reached clinical trial stage yet. 


\section{Targeted Toxins for Glioma Therapy}

Over the past several years, research efforts have focused on the utilization of cellular receptors exclusively over-expressed in brain tumor cells for targeted therapy. It has been reported that human tumors, including established glioma cell lines, primary glioblastoma cell cultures and surgical glioma biopsies express a variant of the IL-13 receptor. This receptor (IL13R $\alpha 2$ ) is different from its physiological counterpart, i.e., IL13/IL4R (170-174). The urokinase-type plasminogen activator (uPA) receptor is also overexpressed in glioblastomas $(170-173,175)$, as well as receptors for growth factors, such as epidermal growth factor (EGF) receptor (176,177). Importantly, since these receptors are virtually absent in the normal brain, they are very attractive targets for targeted therapeutic approaches in glioma, minimizing any putative adverse side effects to normal brain tissue. Thus, ligands of these receptors, such as IL-13, uPA, EGF, and transforming growth factor $\alpha$ (TGF- $\alpha$ ) have been fused to the catalytic and translocation domains of highly cytotoxic bacterial products, including Pseudomonas $(174,177,178)$ and Diphteria toxins $(78,173,175,176)$, in order to selectively kill glioma cells, but preserving surrounding normal brain tissue. These fusion toxins have shown promising results in in vitro and in vivo experiments using murine glioma models and clinical trials have shown that direct interstitial infusion can be used to successfully distribute chimeric toxins in tumors in the CNS, achieving anti-tumor responses without systemic toxicity in patients with malignant brain tumors (179). The chimeric toxin composed of IL-13 and truncated Pseudomonas exotoxin, also termed IL-13 toxin, is currently being used in several clinical trials that recruit patients throughout the country as well as Canada, Germany, Israel, and the Netherlands. The IL-13 toxin has been shown to exert a potent cytotoxic effect in most human glioblastoma cells tested in culture $(174,178,180)$ and in vivo, in human xenografts consisting of glioma cells implanted in the flank of nude mice (181). Moreover, the intratumoral administration of IL13-PE toxin into intracranial human glioma xenografts in mice showed highly cytotoxic effects without undesirable side effects (182). To optimize the targeting of GBM associated IL-13 $\alpha 2$ receptor, human $\mathrm{IL}-13$ (hIL-13) gene has been engineered leading to a mutated form of hIl-13 that exhibits 50 fold higher affinity for the IL$13 \alpha 2$ receptor present in human glioma cells when compared to the wild type IL-13 $(183,184)$. Fusion of this muIL-13 to PE resulted in an even more active cytotoxin in glioma tumors both in vitro and in vivo (183). Importantly, the mull 13 no longer interacts with the principal chain of $\mathrm{L} 4 \mathrm{R}$, thus becoming ineffective in its binding to this receptor and signaling through the physiological IL13/IL4R of normal cells. This in turn decreases the already low toxicity of the chimeric toxin to normal cells (183). Thus, although this mutant has negligible affinity by $\mathrm{IL}-13$ receptor of normal cells, it exerts an enhanced cytotoxic effect towards glioma cells. We are currently developing a gene therapy approach based on IL-13R-targeting, in which a high capacity adenoviral vector encodes for mull-13 fused to the truncated PE toxin and a mutated $\mathrm{L}-4$ that functions as antagonist of the IL13R present in normal cells without interacting with IL13 $\alpha 2 R$ for an enhanced safety profile (Fig. 1) (185). The fact that IL13R $\alpha 2$ is over expressed not only in glioma cells, but also in other malignancies, including renal cell carcinoma (186), ovarian carcinoma (187), colon adenocarcinoma (178), epidermoid carcinoma (178), AIDS-associated Kaposi's sarcoma (188), prostate carcinoma (189) and pancreatic cancer (190), makes IL13R $\alpha 2$ a unique target for anticancer therapy. Gene therapy offers the possibility of making the targeted toxins approach more efficacious and less toxic for GBM therapy, by expressing the genetically engineered toxin under a regulatable promoter, within a viral vector, it would eliminate the need of 


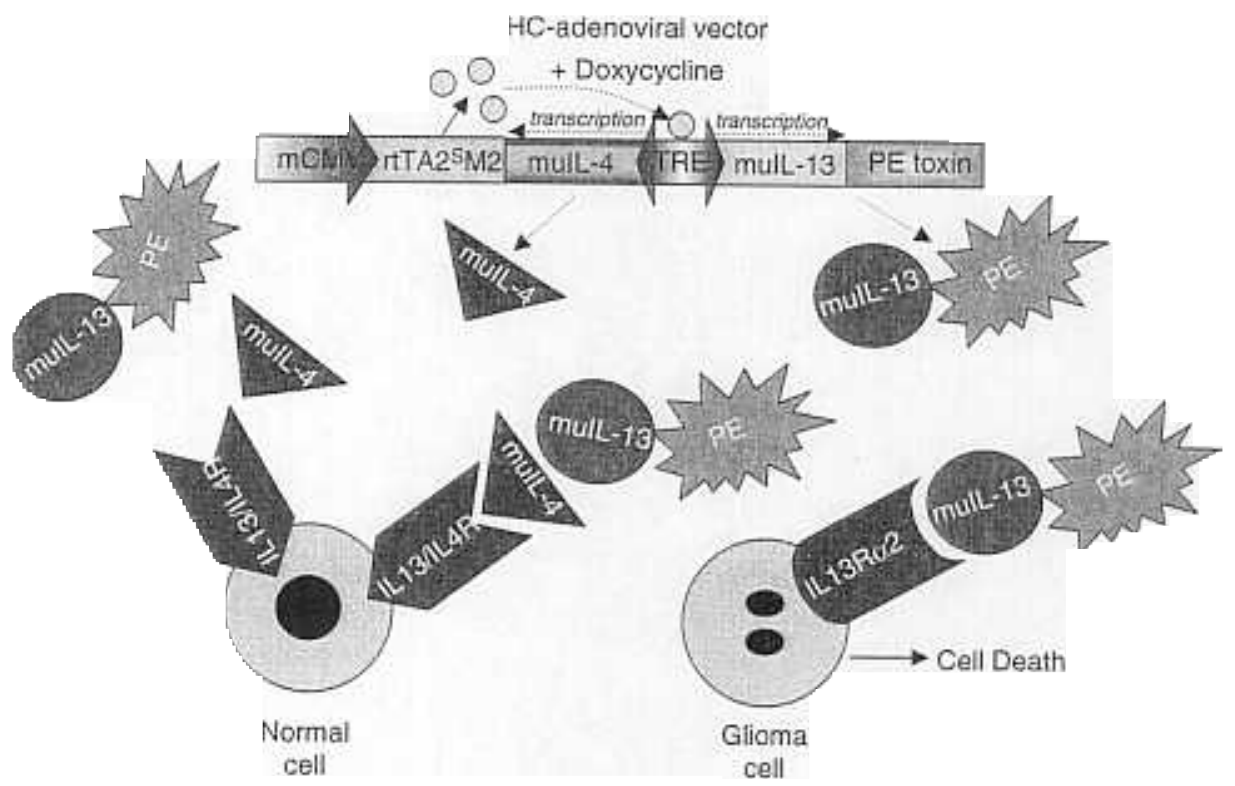

Figure 1 Targeted toxins for glioma gene therapy. Structure of a high capacity adenoviral vectors encoding muIL-13 fused to the truncated PE toxin, which binds and kills glioma cells without affecting normal brain cells. For further safety, this vector includes a mutated IL-4 (muIl- 4 ), which functions as antagonist of the IL13R present in normal cells, without interacting with IL13R $\alpha 2$, thus it prevents mulL-13-PE to interact with normal cells, protecting them from the detrimental effect of the toxin, while it does not affect muL-13-PE binding to glioma cells. Therapeutic trangenes are encoded under the control of the TRE promoter, which is activated by a transactivator (rtTA2SM2) only in the presence of the antibiotic doxycycline, further increasing the safety of this approach. Abbreviations: PE, pseudomonas exotoxin; TRE, tetracycline response element.

repeated treatment due to the short half-life of the therapy, it will also allow the fine regulation of the levels of toxin expressed in case the therapy is no longer needed or to obviate adverse side effects.

\section{VALIDATION OF CANCER GENE THERAPY STRATEGIES IN VITRO AND IN VIVO}

\section{An Overview of Commonly Used Glioma Models}

Accurate experimental models are of paramount importance in developing effective therapies against diseases. A clinically relevant model helps establish the effectiveness of new therapies, such as gene therapy in a pre-clinical setting. In addition, genetic, and biochemical studies of these experimental models may shed light on defects that contribute to the development of brain tumors in humans. Table 1 shows the requirements that an ideal experimental model for glioma should meet (191).

Rodents are routinely used in preclinical studies of glioma and offer many advantages over other vertebrate models, invertebrate models or cell culture models. Unlike many larger mammals, mice, and rats have a high reproductive rate and are easy to handle and maintain. In addition, mice, and rats have been extensively studied in scientific literature and consequently have well-defined genetics, biochemistry, and physiology. 
Table 1 Features of Cell Implantation and Genetic Glioma Models

\begin{tabular}{|c|c|c|}
\hline $\begin{array}{l}\text { Desired features of glioma } \\
\text { animal models }\end{array}$ & Cell implantation models & Genetic models \\
\hline Glial origin & $\nabla$ & $\square$ \\
\hline $\begin{array}{l}\text { Biological similarity to human } \\
\text { gliomas }\end{array}$ & & $\nabla$ \\
\hline $\begin{array}{l}\text { Hystological similarity to human } \\
\text { gliomas (invasion, neovasculari- } \\
\text { zation) }\end{array}$ & \pm & $\nabla$ \\
\hline Intact tumor-host interactions & $\nabla$ & $\nabla$ \\
\hline $\begin{array}{l}\text { Allow detection of antitumoral } \\
\text { immune responses }\end{array}$ & $\nabla$ & $\nabla$ \\
\hline $\begin{array}{l}\text { Non immunogenic in syngeneic } \\
\text { animals }\end{array}$ & $\nabla$ & $\nabla$ \\
\hline $\begin{array}{l}\text { Allow study of human glioma } \\
\text { tumors }\end{array}$ & $\nabla$ & \\
\hline $\begin{array}{l}\text { Allow non-invasive techniques of } \\
\text { tumor progression diagnosis }\end{array}$ & $\nabla$ & \\
\hline $\begin{array}{l}\text { Accurate knowledge of tumor } \\
\text { location }\end{array}$ & $\square$ & \\
\hline $\begin{array}{l}\text { Predictable and reproducible tumor } \\
\text { growth rates }\end{array}$ & $\nabla$ & \\
\hline Similar time to death of animals & $\nabla$ & \\
\hline Enough survival time to test therapy & $\bar{\nabla}$ & 曰 \\
\hline Tumor progression & Fast & Slow \\
\hline Technically easy and not expensive & $\square$ & \\
\hline Available for rat and mice & $\bar{\nabla}$ & Only mice \\
\hline
\end{tabular}

Genomics has further endorsed the use of mice and rats as models for human disease. Most human genes have homologues in rats and mice that share significant sequence homology with their human counterparts. Moreover, the mouse genome is very pliable, and a large number of genetically modified strains have been created, characterized, and maintained either by selectively breeding mice with spontaneous genetic mutations or by using transgenics. Transgenics in particular has established mice as the most commonly used laboratory mammal for studying human disease. Transgenic rats have also been recently created and as this technology progresses, the rat may offer attractive models for GBM preclinical studies.

\section{Early Models of Glioma}

Prior to 1970 , research in glioma was limited by the lack of suitable pre-clinical models to design and test new therapies. DNA alkylating agents, including $\mathrm{N}$-methyl-N-nitrosourea (NMU), generate point mutations in DNA and were found to promote gliomagenesis when injected i.v. into rabbits (192). This observation quickly led to the development of rat models of glioma involving repeated injection of NMU i.v. and subsequent observations for neurological symptoms to appear (193). Although these models are labor intensive and not particularly suited to pre-clinical studies, cell lines were developed from rats and mice injected with NMU. Many of these cell lines grow in vitro and in vivo and quickly gave 
rise to a more versatile pre-clinical model of glioma, using GBM cell lines to develop implantation models in xenogeneic or syngeneic hosts.

\section{Xenograft Models of Glioma}

Many models of glioma currently inoculate mice and rats with exogenous glioma cell lines grown in vitro. These cell lines can either be injected in the periphery giving rise to flank tumors, or alternatively injected directly into the brain of animals. Injection of cells directly into the brain requires a stereotactic device to ensure accurate and reproducible results and is clinically more relevant than flank tumors. However, some experimental designs require the convenient access of flank tumors and consequently researchers utilize both models. In these cases, data should be corroborated using intracranial models to account for differences in the extracellular environments. Exogenous glioma xenografts offer several advantages over other glioma models including highly efficient gliomagenesis, reproducible growth rates, similar time to death for different animals and an accurate knowledge of the site of the tumor. This last point is particularly advantageous in intracranial models of glioma where injection sites must be carefully chosen to overlap with the site of the tumor. Furthermore, xenograft models of glioma have been widely used and are well characterized in the literature. However, these models also have a number of important limitations that must be considered when choosing a suitable model for gliomagenesis. Paramount of these is that the majority of exogenous glioma xenografts utilize cell lines originally derived from human glioma. Consequently, immune rejection of the implanted tumor can alter the progression of the disease and decrease the clinical accuracy of the model. To limit this problem, human GBM models have been developed in immune-deficient mice and/or rats. Most models currently use cell lines originally derived from the same animal strain; these syngeneic xenografts generally have minimal non-specific immune reactivity. Another limiting factor with these models is the absence of developing stages of glioma. Therefore, while these models are useful to estimate the clinical effectiveness of various transgenes in gene therapy, they are not well designed to understand initial events that occur during gliomagenesis. In addition, promising results should be verified in more stringent models of glioma before progressing to clinical trials in human patients.

\section{Rat Intracranial Glioma Cell Implantation Models}

Intracranial injection of cell lines into rats has been used as to model glioma since the early 1970s (194). A wide diversity of cell lines have been developed for this purpose. Some of the most widely used rat brain tumor models include 9L gliosarcoma, CNS-1 glioma, C6 glioma, F98 glioma, RG2 glioma, and RT-2 induced glioma (195). The most widely used intracranial glioma model has been the $9 \mathrm{~L}$ gliosarcoma model. This model uses $9 \mathrm{~L}$ gliosarcoma cells originally derived from $C D$ Fischer rats injected i.v. with methylnitrosourea to promote spontaneous gliomagenesis. Early studies in gene therapy primarily used this model and some spectacular results were observed (196), (Nam M, Brain Res 1996). However, this model is highly immunogenic and it has since been demonstrated that an immune response against the $9 \mathrm{~L}$ gliosarcoma is the principal means by .which non-transduced cells are killed by HSV1-TK/ganciclover treatment. Consequently this model is not optimal for studies involving gene therapy, especially approaches that aim to harness immunotherapeutic targets $(197,198)$. Another cell line derived from rats injected with methylnitrosourea (MNU) (C6) was developed. 
Unfortunately, the C6 glioma cell line was originally developed in an outbred Wistar rat and consequently there is no syngeneic host that can be used to propragate it. Consequently, C6 is immunogenic in most hosts and like $9 \mathrm{~L}$ gliosarcoma cells this severely limits the usefuiness of C6 glioma models in gene therapy (195). Recently, the CNS-1 glioma cell line was derived from an inbred Lewis rat that had been injected with MNU in a similar fashion to both $9 \mathrm{~L}$ and $\mathrm{C6}$ glioma cells. However, unlike $9 \mathrm{~L}$ cells the CNS-1 glioma stains positive for GFAP and S-100. CNS-1 cells have in vivo growth rates and histology that more closely resemble human glioma than 9L cells. Furthermore, CNS1 cells are not immunogenic in vivo in Lewis rats and therefore are ideally suited for pre-clinical testing (Fig. 2) (199).

An alternative approach was utilized in the development of F98 and RG2 cell lines. The mutagen of choice was not MNU but instead was ethylnitrosourea (ENU) in both cases. Both of these glioma cell lines are non-immunogenic. F98 glioma cells were originally from offspring of a pregnant CD Fisher rat and are remarkably similar to human glioma in many ways. They are very weakly immunogenic, they display an infiltrative pattern of growth similar to human glioma and as few as 10 cells invariably kill animals when inoculated intracranially in vivo. RG2 cells were produced in a similar fashion and are non-immunogenic in syngeneic Fischer rats (200). The invasive pattern of growth and refractory nature to chemotherapeutic agents are advantages to using this model in assessing the effectiveness of novel gene therapeutic agents.

\section{Mouse Intracranial Glioma Cell Implantation Models}

Historically, the rat was the rodent of choice for pre-clinical models of glioma due to its larger size and well documented physiology and anatomy. However, in the genomic era with the advent of transgenics, the mouse has superseded the rat as the most popular model of human diseases. Many of these models seek to explore the early events of gliomagenesis by mutating key regulatory genes using transgenics and in doing so develop more accurate
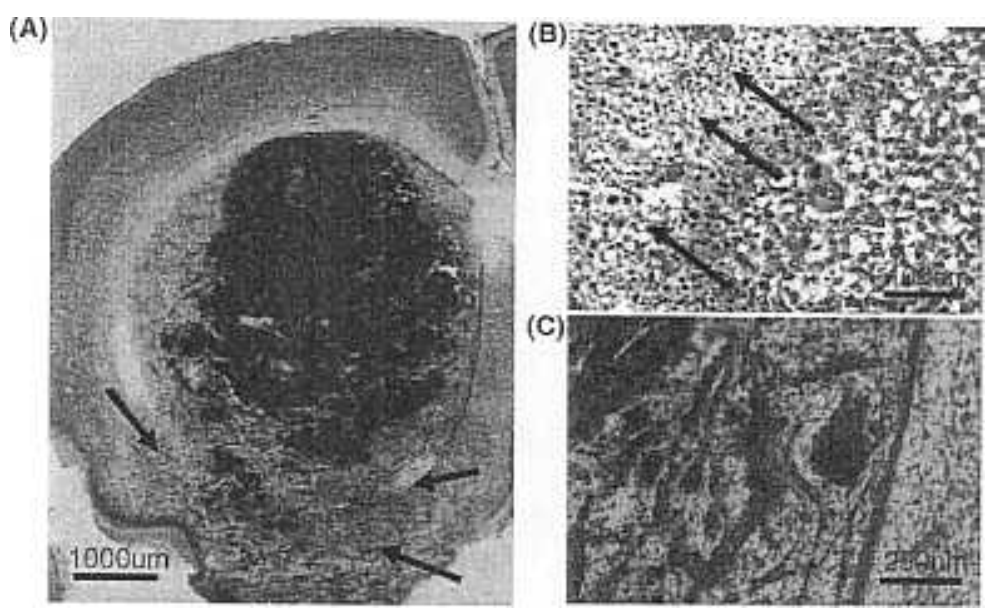

Figure 2 (See color insert) CNS-1 tumor histology. 5000 CNS-1 glioma cells were implanted in the striatum of syngeneic Lewis rats. Animals become moribund within 3 weeks of implantation. (A) Nissl staining of a brain section showing a CNS-1 tumor from an untreated moribund animal. Note areas of infiltration (arrows). (B) Hematoxilin/eosin stained brain section showing a CNS-1 tumor from an untreated moribund animal. The arrow indicates an area of cell death within the tumor. (C) Nissl stained brain section showing areas of tumoral cell infiltration in the same animal pictured in $\mathbf{A}$. 
pre-clinical models of human glioma. Also number of intracranial xenograft models have also been developed to accelerate the discovery of novel promising therapies. Unfortunately many of the earlier models often used human glioma xenografts (i.e., SF-9o295, U-251 or D54) or rat glioma xenografts (primarily C6) transplanted into immunocompromised mice. Immune-mediated events before, during, and after therapy cannot be observed in these models, limiting their usefulness. A number of syngeneic models have been developed. The first model used was glioma 26 (GL-26). These cells were found to be non-immunogenic when injected either subcutaneously or intracranially into C57/BL6 mice and this model is still commonly used today (Fig. 3) (201). Another mouse glioma cell line called GL261, also derived from C57/BL6 mice, has similar characteristics to GL26 cells and both these cell lines are useful for studying the response of brain tumors to immunotherapy (202). More recently, other models have been developed, including a syngeneic glioma cell line derived from spontaneous tumor in a transgenic mouse model called 4C8. These cells express GFAP and the histology was densely cellular, and developed a pseudopallisading pattern of necrosis. All these features are commonly found in human glioblastoma, making this a very useful model for testing and developing novel gene therapeutic agents (203). Although these models are useful in pre-clinical studies of anti-tumor therapies, the main focus has centered on understanding the molecular pattern of gliomagenesis by altering genes believed to play

(A)
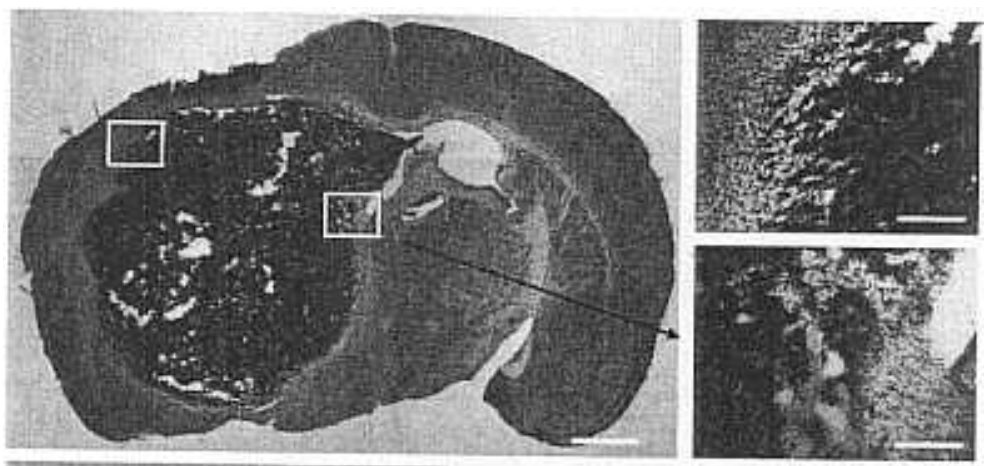

(B)
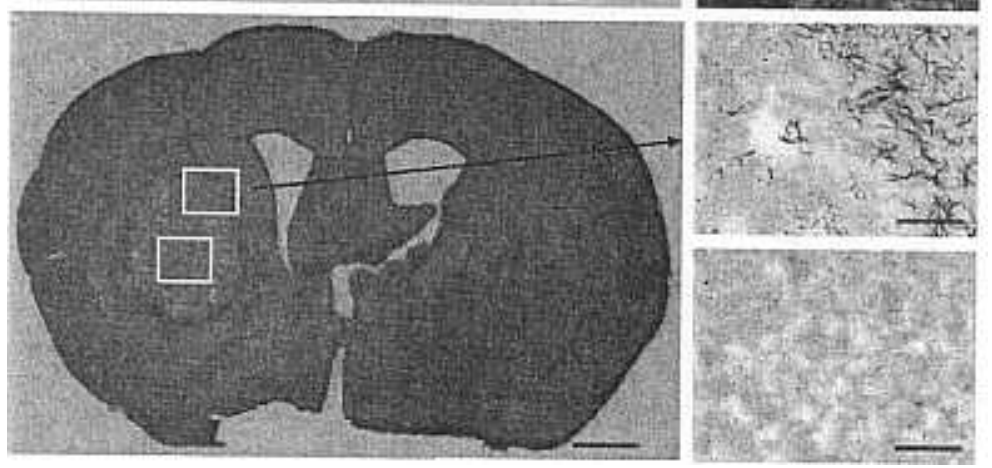

Figure 3 (See color insert) C57/BL6 mice were challenged with 20000 GL26 cells injected into the striatum. The animals were moribund after 25-30 days. (A) Nissel staining of a brain section showing a GL26 tumor from an untreated moribund animal. Scale bars: $1000 \mu \mathrm{m}$ in low magnification shots, $250 \mu \mathrm{m}$ in higher magnification shots. (B) GFAP immunostaining of a brain section from an untreated moribund animal shows activated astrocytes. A higher magnification picture shows infiltration of tumor cells into the surrounding CNS tissue. Scale bars: $1000 \mu \mathrm{m}$ in low magnification shots; $100 \mu \mathrm{m}$ in higher magnification shots. 
an important role. Transgenics in particular have led to the development of a wide variety of mouse models of glioma that are closer approximations of human disease.

\section{Genetic Modelling of Glioma Formation}

Researchers have aspired to develop mouse glioma models by deleting (knockout) or inserting (transgenic) genes commonly mutated in human disease. The aim of this approach is twofold. Firstly, a greater insight into the key factors contributing to gliomagenesis and disease progression can be elucidated from these studies. This may lead to the identification of key targets for gene therapy or more conventional drugs. Secondly, more accurate pre-clinical models of the human disease should improve the process of drug testing and development for treating glioma. Recently, a number of mouse strains have been developed that mimic many of the histological and pathological features of human gliomas. Furthermore, many of these models consistently give rise to brain tumors that strongly resemble particular classes or types of human glioma. These models have enormous potential for understanding the different genetic alterations and cellular precursors of glioma tumors and in refining novel therapies, including gene therapy, in a relevant pre-clinical model. In this section we will discuss the recently developed and most promising models of glioma.

\section{Transgenic Mouse Models of Glioma}

Two transgenic mice in particular have proved very useful in the study of gliomagenesis and have also been used to evaluate glioma therapies. In these mice, the oncogenes v-src and ${ }^{\mathrm{V} 12} \mathrm{H}$-Ras have been introduced into murine germlines under the control of the GFAP promoter. GFAP expression is confined to cells of the astroglial lineage and this regulation is under control of the highly specific GFAP promoter. Consequently, the oncogenic potential of $\mathrm{v}$-src or ${ }^{\mathrm{v} 12} \mathrm{H}$-Ras is also confined to astroglial cells in this model. One line derived from ${ }^{\mathrm{v} 12} \mathrm{H}$-Ras transgenic mice develop solitary tumors that closely resemble low grade astrocytoma (grade II), whereas animals homozygous for the transgene develop multifocal tumors that represent anaplastic astrocytoma (grade III). Similarly transgenic mice expressing v-src under the control of GFAP promoter also develop tumors that resemble human astrocytomas (grade II) (204). Tumors in these models further develop into grade III tumors and ultimately to glioblastoma (grade IV). This order of events closely follows progression of glioma in humans. Furthermore, tumors in ${ }^{\mathrm{v} 12} \mathrm{H}$-Ras transgenic mice displayed many molecular changes commonly associated with glioblastoma in humans including elevated EGFR and MDM2 and CDK4 expression, elevated AKT activity, and decreased levels of INK4A, ARF, and PTEN expression $(205,206)$. Additional mutations in tumor suppressor genes and proto-oncogenes have also been developed and these in general accelerate the development of glioblastoma (206). Consequently, these mice closely model glioma progression in humans and may be more accurate indicators of gene therapeutic agents in pre-clinical studies.

\section{Knockout Mouse Models of Glioma}

In general, mutations in signal transduction pathways regulating the cell cycle or RTK activity are evident in many if not all gliomas and play a fundamental role in the progression of the disease. Of the many mouse strains developed with mutations in genes commonly altered in human glioma, only germline deletion of the tumor suppressor genes p53 and NF1 alone was found to increase the susceptibility of mice to astrocytoma and glioblastoma (207). This supports the work of others suggesting that p53 mutation or 
deletion is a very early event in gliomagenesis (11). INK4A and ARF have also been studied as regulators of gliomagenesis. Although deletion of either or both gene products alone is not sufficient to induce glioma formation in mice, somatic transfer of the RTK PDGF into astrocytes and nestin-producing CNS progenitor cells greatly enhances the appearance of mixed oligoastrocytomas and oligodendrogliomas, respectively (208). This supports the conclusions of others that disregulation of the cell cycle induces a change in phenotype of glioma from slowly proliferating grade II to rapidly proliferating grade III tumors. However, initial growth factor independence is required to promote gliomagenesis (27).

\section{CLINICAL TRIALS}

Clinical trials are scientifically designed experiments to determine how efficient new treatment modalities would affect disease outcome and progression in human patients. Many therapeutic formulations can be used in clinical trials such as chemotherapeutic drugs, surgical procedures or gene therapy. The majority of brain tumor clinical trials involve radiation therapy or chemotherapy. There are three different phases (Phase I, II, III) that clinical trials must encompass in order to answer all the needed research and therapeutic questions. Phase I trials determine the best treatment schedule and the best dose of treatment and importantly the safety of the proposed treatment. The effect of the treatment on the actual brain tumor is not the primary issue while safety, dosage, and side effects are. A small trial size is used due to the uncertainties. Phase II trials determine the effect of the treatment on the brain tumor (i.e., does the tumor size shrink?). A safe dosage has been established in Phase I so investigating the anticancer effect is the primary goal. Phase III trials compare the new treatment to already existing treatments. A much larger trial size is used in phase III trials because these are proposed as established treatments that will help reduce the tumor size and prolong patients' life span. There are definite benefits to being a part of a clinical trial. Even if patients do not get selected for receiving the new treatment, they will still receive the best possible treatments for brain cancer available.

Table 2 summarizes the advantages and benefits of gene therapy vectors that already tested in clinical trials. One of the main gene therapy approaches that have been implemented in clinical trials is the use of the herpes simplex virus gene for HSV1-TK as a conditional cytotoxic strategy. The gene is expressed in all infected cells, but it will only cause cytotoxicity in the presence of the prodrug, GCV, in dividing, tumor cells and it will not affect non-dividing, normal brain cells. After patients are administered the HSV1-TK gene encoded withing a viral vector, they are given the antiviral drug, GCV. The HSV1TK gene product phosphorylates GCV and intracellular kinases convert it to GCV triphosphate that intercalates in replicating DNA causing cell death. Most of the clinical trials using HSV1-TK and GCV have provided positive data for the outcome of brain tumor patients (209-211). The intratumoral injection of retrovirus-packaging cells as well as adenoviruses encoding HSV1-TK followed by GCV administration has been tested for glioma treatment in Phase I/II clinical trials $(213,214)$. Human glioma cells express CAR and integrin $\alpha \mathrm{V}$ on their cell surface, which mediate adenoviral attachment and internalization, therefore making Ad attractive vectors for GBM gene therapy approaches (Fig. 4). Both therapies were well tolerated and safe $(152,212,213)$, with adenoviral vectors encoding TK observed to be more efficient than retrovirus vectors, based on tumor re-growth three months after gene therapy and extended glioma-bearing patients' survival (212). Also, since delivery of retrovirus vectors is achieved by implantation of xenograft 
Table 2 Gene Therapy Vectors Tested in Clinical Trials for Glioma Treatment

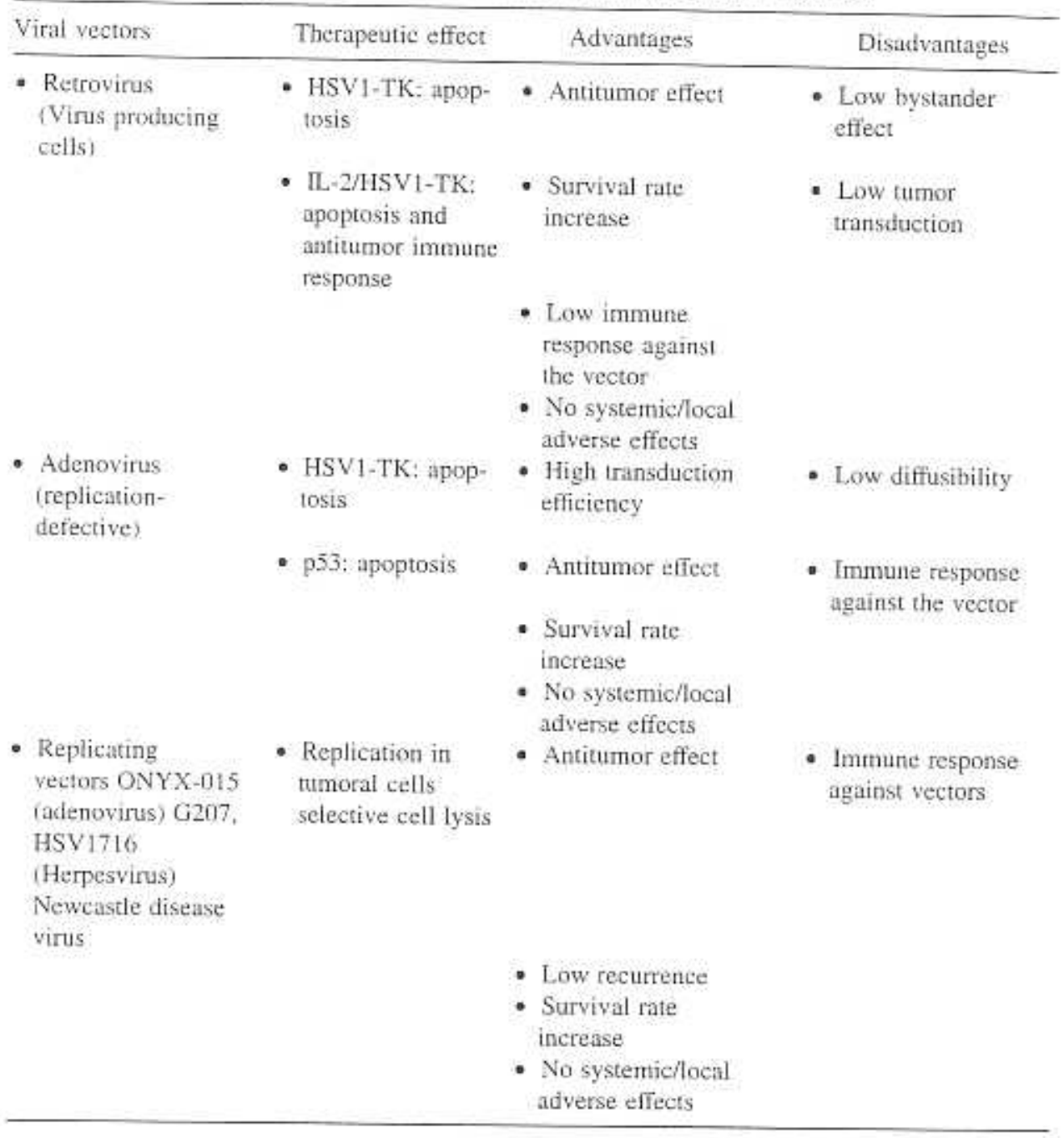

virus-producing cells rather than the retrovirus (152), this approach adds the hazards of xenogeneic transplant rejection, absent in adenoviral-based therapies. A recent Phase III clinical trial compared the efficacy of HSV1-TK delivery using adenoviral gene therapy with standard care of glioma patients, consisting of radical excision followed by radiotherapy (214). The intracranial injection of the adenoviral vector encoding HSV1-TK followed by the intravenous administration of ganciclovir (GCV) increased the survival time of glioma from 40 to 70 weeks, without adverse side effects (214). In summary, intratumoral adenoviral delivery of TK, combined with GCV is a potential new treatment for operable primary or recurrent high-grade glioma.

Phase I trials consisting in the intratumoral injection of an adenoviral vector to deliver the p53 gene in glioma cells have also led to interesting results. The toxicity of this treatment was minimal and there was no evidence of systemic viral dissemination. The adenoviral p53 trial showed that exogenous p53 was expressed in the nuclei of glioma 
(A)
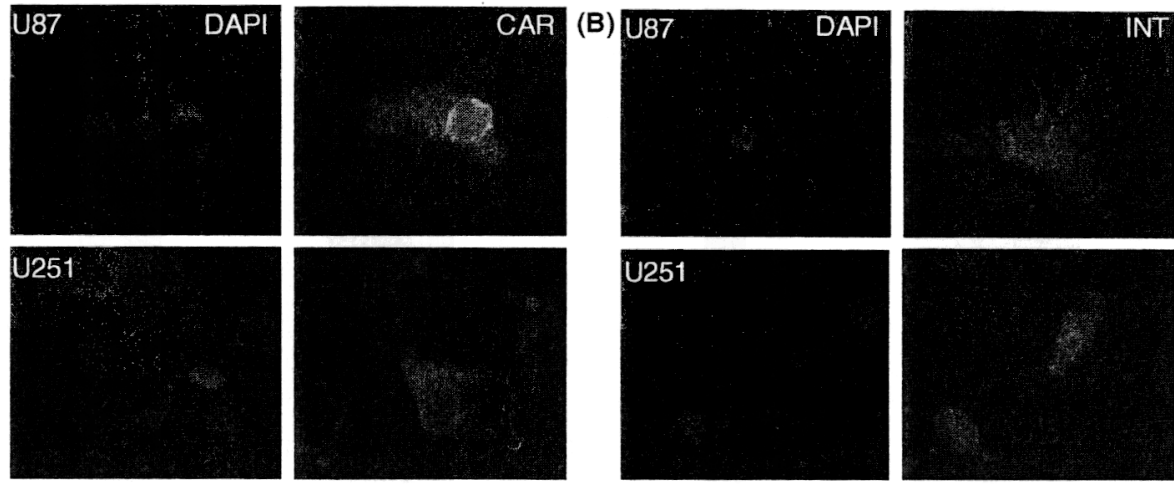

Figure 4 (See color insert) Expression of adenoviral receptors in human glioma cells. (A) The coxsackie-adenoviral receptor (CAR) and (B) Integrine $\alpha \mathrm{V}$ [INT] expression were detected in U251 and U87 cells by immunofluorescence. Left panels show nuclei stained with DAPI and right panels show the expression of the receptors using indirect immunofluorescence.

cells and activated a downstream pathway that induces apoptosis and prevents the tumor from expanding (20). The only downfall of this therapy was that the transgene expression was not widespread and therefore only the tumor cells close to the injection site were killed. Further work to enhance the distribution of the therapeutic gene will increase the possibilities of this therapy considerably.

A recent phase I clinical trial has been conducted to determine the safety of ONYX-015, a mutated adenovirus that is able to replicate selectively in and kill tumor cells, but not normal cells $(215,216)$. The dose-escalation trial showed intra-cerebral injections of ONYX-015 to be very well tolerated by glioma-bearing patients without any adverse side effects attributable to the viral vector, even at doses as high as $10^{10} \mathrm{pfu}(217)$. Although therapeutic efficacy of all these novel gene therapy approaches will have to await larger trials, they provide a solid scientific rationale for additional studies of adenoviral-based gene therapy for brain tumors.

Replicating herpes simplex viral (HSV) vectors have also been used as replication competent vectors to treat brain tumors in clinical trials. HSV-G207 vector contains two mutations within the virus that confer specificity of G207 for dividing in tumoral cells, while intact HSV1-TK gene provides a mechanism to control any herpetic infection that may arise from use of these replicating vectors. In phase one clinical trials with G207 was intratumorally injected in patients with progressive or recurrent glioma (218). MTD was not established as the highest level $3 \times 10^{9}$ pfu was well tolerated and no herpetic, encephalic or inflammatory effects were observed. Although one patient seroconverted, exhibiting serum antibodies anti-HSVI after treatment, no systemic toxicity attributable to G207 treatment was observed. Four patients survived at the end of the trial, while the mean survival from diagnosis to death increased to 15.9 months.

Another replicating HSV vector, HSV1716, showed to be unable to replicate in neurons while replicates and lyses glioma cells. In a phase one clinical trial, HSV1716 was intratumorally injected in glioma patients. The MTD for this vector was not determined as up to $1 \times 10^{5}$ pfu were tolerated well with no encephalitis or herpetic complications, all patients remaining seronegative for HSV-1 (219). In an additional trial, recurrent patient tumors were examined after injection of HSV1716 and virus was detectible by 
semiquantitative PCR (220). Even in inoculated tumors for which virus was not detectible, reinfection in vitro triggered low level HSV1716 viral shedding indicating persistent longterm effects may be possible (221). HSV1716 was also intracranially injected after glioma resection to eliminate residual tumor cells (222). Of 12 patients, three survived, one died of non related events, and eight died after tumor progression. No treatment related toxicities were observed. Further clinical trials are ongoing.

Replication-competent Newcastle disease virus (NDV) has also been used in clinical trials. Glioma tumor cells taken from patients were infected with NDV, irradiated, and used to vaccinate the patient, who survived significantly longer than non-vaccinated controls and the therapy was well tolerated $(223,224)$.

Several clinical trials have been testing the potential of chimeric toxins targeting receptor that are overexpressed in human gliomas. Clinical trials testing the antitumoral potential of the intratumoral administration of $\mathrm{IL}-13$ toxin, consisting in $\mathrm{IL}-13$ fused to Pseudomonas exotoxin, are currently being developed in the United States, Canada, Germany, Israel, and the Netherlands. In a PhaseI/II clinical trial, patients with glioblastoma multiforme were intratumorally injected with $\mathrm{IL}-13$ toxin eight days before surgical resection (225). Necrotic areas were found in the tumors from half the patients, suggesting that the toxin successfully induced tumoral cell death.

The chimeric toxin composed of IL-4 and Pseudomonas exotoxin was intracranially administered to patients with recurrent glioblastoma multiforme in Phase I and Phase I/II clinical trials. The intratumoral administration of $\mathrm{IL}-4$ cytotoxin showed an acceptable safety profile, being well tolerated at low doses (226). These studies suggested that this cytotoxin has anti-tumor activity, inducing necrosis in the tumor parenchyma, without histological evidence of toxicity to normal brain tissues (227). Although local toxicity, such as intracranial edema, was reported, it seems to be due to tumor necrosis or occasionally to the volume of infusion.

Transferrin-diphteria toxin was locally administered by high-flow interstitial microinfusion to patients with recurrent malignant brain tumors, which were refractory to conventional therapy (179). Although episodes of local toxicity in some of the patients were reported, direct interstitial infusion was shown to successfully distribute the toxin in the tumor and infiltrated brain areas, achieving anti-tumor responses without severe neurologic or systemic toxicity (228).

A chimeric toxin consisting of TGF and Pseudomonas toxin was tested in a Phase I trial to determine its dose limiting toxicity. The chimeric toxin was determined by convection-enhanced delivery in 20 patients with recurrent malignant brain tumors. In this trial the maximal tolerated dose could not be established, being the overall median survival 23 weeks after intracranial administration of the toxin (229).

\section{ACKNOWLEDGMENTS}

Gene therapy projects for neurological diseases are funded by the National Institutes of Health/National Institute of Neurological Disorders and Stroke Grant 1R01 NS44556.01, National Institute of Diabetes and Digestive and Kidney Diseases 1 RO3 TW006273-01 to M.G.C.; National Institutes of Health/National Institute of Neurological Disorders and Stroke Grant 1 RO1 NS 42893.01, U54 NS045309-01, and 1R21 NS047298-01 and Bram and Elaine Goldsmith Chair In Gene Therapeutics to P.R.L.; and The Linda Tallen \& David Paul Kane Annual Fellowship to M.G.C and P.R.L. We also thank the generous funding our Institute receives from the Board of Governors at Cedars-Sinai Medical 
Center. We thank the support and academic leadership of S. Melmed, R. Katzman, and D. Meyer for their superb administrative and organizational support.

\section{REFERENCES}

1. Baldwin RT, Preston-Martin S. Epidemiology of brain tumors in childhood-a review. Toxicol Appl Pharmacol 2004; 199:118-131.

2. McCance KL, Huether SE. 3rd ed. Pathophysiology: The Biologic Basis for Disease in Adults and Children. St. Louis: Mosby, 1998.

3. Stedman TL. Stedman's medical dictionary. 27th ed. Philadelphia: Lippincott Williams \& Wilkins, 2000.

4. Castro MG, Cowen R, Williamson IK, David A, Jimenez-Dalmaroni MJ, Yuan X, Bigliari A, Williams JC, Hu J, Lowenstein PR. Current and future strategies for the treatment of malignant brain tumors. Pharmacol Ther 2003; 98:71-108.

5. Halperin EC. Pediatric radiation oncology. 3rd ed. Philadelphia: Lippincott Williams \& Wilkins, 1999.

6. Kaba SE, Kyritsis AP. Recognition and management of gliomas. Drugs 1997; 53:235-244.

7. Grossman SA, Batara JF. Current management of glioblastoma multiforme. Semin Oncol 2004; 31:635-644.

8. Merlo A. Genes and pathways driving glioblastomas in humans and murine disease models. Neurosurg Rev 2003; 26:145-158.

9. Hisada M, Garber JE, Fung CY, Fraumeni JF, Jr., Li FP. Multiple primary cancers in families with Li-Fraumeni syndrome. J Natl Cancer Inst 1998; 90:606-611.

10. Watkins D, Rouleau GA. Genetics, prognosis and therapy of central nervous system tumors. Cancer Detect Prev 1994; 18:139-144.

11. Louis DN. The p53 gene and protein in human brain tumors. J Neuropathol Exp Neurol 1994; 53:11-21.

12. Asai A, Miyagi Y, Sugiyama A, Gamanuma M, Hong SH, Takamoto S, Nomura K, Matsutani M, Takakura K, Kuchino Y. Negative effects of wild-type p53 and s-Myc on cellular growth and tumorigenicity of glioma cells. Implication of the tumor suppressor genes for gene therapy. J Neurooncol 1994; 19:259-268.

13. Badie B, Drazan KE, Kramar MH, Shaked A, Black KL. Adenovirus-mediated p53 gene delivery inhibits 9L glioma growth in rats. Neurol Res 1995; 17:209-216.

14. Kock H, Harris MP, Anderson SC, et al. Adenovirus-mediated p53 gene transfer suppresses growth of human glioblastoma cells in vitro and in vivo. Int J Cancer 1996; 67:808-815.

15. Gjerset RA, Turla ST, Sobol RE, et al. Use of wild-type p53 to achieve complete treatment sensitization of tumor cells expressing endogenous mutant p53. Mol Carcinog 1995; 14:275-285.

16. Dorigo O, Turla ST, Lebedeva S, Gjerset RA. Sensitization of rat glioblastoma multiforme to cisplatin in vivo following restoration of wild-type p53 function. J Neurosurg 1998; 88:535-540.

17. Badie B, Kramar MH, Lau R, Boothman DA, Economou JS, Black KL. Adenovirus-mediated p53 gene delivery potentiates the radiation-induced growth inhibition of experimental brain tumors. J Neurooncol 1998; 37:217-222.

18. $\mathrm{Li} \mathrm{H}$, Alonso-Vanegas $\mathrm{M}$, Colicos $\mathrm{MA}$, et al. Intracerebral adenovirus-mediated p53 tumor suppressor gene therapy for experimental human glioma. Clin Cancer Res 1999; $5: 637-642$.

19. Cirielli C, Inyaku K, Capogrossi MC, Yuan X, Williams JA. Adenovirus-mediated wild-type p53 expression induces apoptosis and suppresses tumorigenesis of experimental intracranial human malignant glioma. J Neurooncol 1999; 43:99-108.

20. Lang FF, Bruner JM, Fuller GN, et al. Phase I trial of adenovirus-mediated p53 gene therapy for recurrent glioma: biological and clinical results. J Clin Oncol 2003; 21:2508-2518. 
21. Chen J, Willingham $T$, Shuford M, et al. Effects of ectopic overexpression of p21(WAF1/CIP1) on aneuploidy and the malignant phenotype of human brain tumor cells. Oncogene 1996; 13:1395-1403.

22. Fueyo J, Gomez-Manzano C, Yung WK, et al. Overexpression of E2F-1 in glioma triggers apoptosis and suppresses tumor growth in vitro and in vivo. Nat Med 1998; 4:685-690.

23. Wang TJ, Huang MS, Hong CY, Tse V, Silverberg GD. Comparisons of tumor suppressor p53, p21, and p16 gene therapy effects on glioblastoma tumorigenicity in situ. Biochem Biophys Res Commun 2001; 287:173-180.

24. Bischoff JR, Kim DH, Williams A, et al. An adenovirus mutant that replicates selectively in p53-deficient human tumor cells. Science 1996; 274:373-376.

25. Heise C, Sampson-Johannes A, Williams A, McCormick F, Von Hoff DD, Kirn DH. ONYX015, an E1B gene-attenuated adenovirus, causes tumor-specific cytolysis and antitumoral efficacy that can be augmented by standard chemotherapeutic agents. Nat Med 1997; 3:639-645.

26. Geoerger B, Grill J, Opolon P, et al. Potentiation of radiation therapy by the oncolytic adenovirus dl1520 (ONYX-015) in human malignant glioma xenografts. Br J Cancer 2003; 89:577-584.

27. Maher EA, Furnari FB, Bachoo RM, et al. Malignant glioma: genetics and biology of a grave matter. Genes Dev 2001; 15:1311-1333.

28. Sherr CJ. Cancer cell cycles. Science 1996; 274:1672-1677.

29. Schmidt EE, Ichimura K, Reifenberger G, Collins VP. CDKN2 (p16/MTS1) gene deletion or CDK4 amplification occurs in the majority of glioblastomas. Cancer Res 1994; 54:6321-6324.

30. Ueki K, Ono Y, Henson JW, Efird JT, Von Deimling A, Louis DN. CDKN2/p16 or RB alterations occur in the majority of glioblastomas and are inversely correlated. Cancer Res 1996; 56:150-153.

31. Zhang X, Multani AS, Zhou JH, et al. Adenoviral-mediated retinoblastoma 94 produces rapid telomere erosion, chromosomal crisis, and caspase-dependent apoptosis in bladder cancer and immortalized human urothelial cells but not in normal urothelial cells. Cancer Res 2003; 63:760-765.

32. Riley DJ, Nikitin AY, Lee WH. Adenovirus-mediated retinoblastoma gene therapy suppresses spontaneous pituitary melanotroph tumors in Rb+/- mice. Nat Med 1996; 2:1316-1321.

33. Fueyo J, Gomez-Manzano C, Alemany R, et al. A mutant oncolytic adenovirus targeting the $\mathrm{Rb}$ pathway produces anti-glioma effect in vivo. Oncogene 2000; 19:2-12.

34. Lee SH, Kim MS, Kwon HC, et al. Growth inhibitory effect on glioma cells of adenovirusmediated p16/INK4a gene transfer in vitro and in vivo. Int J Mol Med 2000; 6:559-563.

35. Fueyo J, Gomez-Manzano C, Yung WK, et al. Adenovirus-mediated p16/CDKN2 gene transfer induces growth arrest and modifies the transformed phenotype of glioma cells. Oncogene 1996; 12:103-110.

36. Simon M, Simon C, Koster G, Hans VH, Schramm J. Conditional expression of the tumor suppressor p16 in a heterotopic glioblastoma model results in loss of pRB expression. J Neurooncol 2002; 60:1-12.

37. Garkavtsev I, Kozin SV, Chernova O, et al. The candidate tumour suppressor protein ING4 regulates brain tumour growth and angiogenesis. Nature 2004; 428:328-332.

38. Rege TA, Fears CY, Gladson CL. Endogenous inhibitors of angiogenesis in malignant gliomas: nature's antiangiogenic therapy. Neuro-oncol 2005; 7:106-121.

39. Chang SM, Lamborn KR, Malec M, et al. Phase II study of temozolomide and thalidomide with radiation therapy for newly diagnosed glioblastoma multiforme. Int J Radiat Oncol Biol Phys 2004; 60:353-357.

40. Baumann F, Bjeljac M, Kollias SS, et al. Combined thalidomide and temozolomide treatment in patients with glioblastoma multiforme. $J$ Neurooncol 2004; 67:191-200.

41. Morabito A, Fanelli M, Carillio G, Gattuso D, Sarmiento R, Gasparini G. Thalidomide prolongs disease stabilization after conventional therapy in patients with recurrent glioblastoma. Oncol Rep 2004; 11:93-95. 
42. Fine HA, Wen PY, Maher EA, et al. Phase II trial of thalidomide and carmustine for patients with recurrent high-grade gliomas. J Clin Oncol 2003; 21:2299-2304.

43. Puduvalli VK, Sawaya R. Antiangiogenesis-therapeutic strategies and clinical implications for brain tumors. J Neurooncol 2000; 50:189-200.

44. Chen $\mathrm{QR}$, Zhang L, Gasper W, Mixson AJ. Targeting tumor angiogenesis with gene therapy. Mol Genet Metab 2001; 74:120-127.

45. Montesano R, Vassalli JD, Baird A, Guillemin R, Orci L. Basic fibroblast growth factor induces angiogenesis in vitro. Proc Natl Acad Sci USA 1986; 83:7297-7301.

46. Szabo $S$, Sandor $Z$. The diagnostic and prognostic value of tumor angiogenesis. Eur J Surg Suppl 1998;99-103.

47. Yukawa H, Takahashi JC, Miyatake SI, et al. Adenoviral gene transfer of basic fibroblast growth factor promotes angiogenesis in rat brain. Gene Ther 2000; 7:942-949.

48. Ke LD, Shi YX, Im SA, Chen X, Yung WK. The relevance of cell proliferation, vascular endothelial growth factor, and basic fibroblast growth factor production to angiogenesis and tumorigenicity in human glioma cell lines. Clin Cancer Res 2000; 6:2562-2572.

49. Plate KH, Risau W. Angiogenesis in malignant gliomas. Glia 1995; 15:339-347.

50. Stratmann A, Machein MR, Plate KH. Anti-angiogenic gene therapy of malignant glioma. Acta Neurochir Suppl (Wien) 1997; 68:105-110.

51. Leung DW, Cachianes G, Kuang WJ, Goeddel DV, Ferrara N. Vascular endothelial growth factor is a secreted angiogenic mitogen. Science 1989; 246:1306-1309.

52. Keck PJ, Hauser SD, Krivi G, et al. Vascular permeability factor, an endothelial cell mitogen related to PDGF. Science 1989; 246:1309-1312.

53. Saleh M, Stacker SA, Wilks AF. Inhibition of growth of $\mathrm{C} 6$ glioma cells in vivo by expression of antisense vascular endothelial growth factor sequence. Cancer Res 1996; 56:393-401.

54. Sasaki M, Wizigmann-Voos S, Risau W, Plate KH. Retrovirus producer cells encoding antisense VEGF prolong survival of rats with intracranial GS9L gliomas. Int J Dev Neurosci 1999; 17:579-591.

55. Machein MR, Risau W, Plate KH. Antiangiogenic gene therapy in a rat glioma model using a dominant-negative vascular endothelial growth factor receptor 2. Hum Gene Ther 1999; 10:1117-1128.

56. O'Reilly MS, Boehm T, Shing Y, et al. Endostatin: an endogenous inhibitor of angiogenesis and tumor growth. Cell 1997; 88:277-285.

57. O'Reilly MS, Holmgren L, Shing Y, et al. Angiostatin: a novel angiogenesis inhibitor that mediates the suppression of metastases by a Lewis lung carcinoma. Cell 1994; 79:315-328.

58. Peroulis I, Jonas N, Saleh M. Antiangiogenic activity of endostatin inhibits C6 glioma growth. Int J Cancer 2002; 97:839-845.

59. Yamanaka R, Zullo SA, Ramsey J, et al. Induction of therapeutic antitumor antiangiogenesis by intratumoral injection of genetically engineered endostatin-producing. Semliki Forest virus. Cancer Gene Ther 2001; 8:796-802.

60. Ma HI, Lin SZ, Chiang YH, et al. Intratumoral gene therapy of malignant brain tumor in a rat model with angiostatin delivered by adeno-associated viral (AAV) vector. Gene Ther 2002; 9:2-11.

61. Tanaka T, Cao Y, Folkman J, Fine HA. Viral vector-targeted antiangiogenic gene therapy utilizing an angiostatin complementary DNA. Cancer Res 1998; 58:3362-3369.

62. Tanaka T, Manome Y, Wen P, Kufe DW, Fine HA. Viral vector-mediated transduction of a modified platelet factor $4 \mathrm{cDNA}$ inhibits angiogenesis and tumor growth. Nat Med 1997; 3:437-442.

63. Witte JS, Palmer LJ, O'Connor RD, Hopkins PJ, Hall JM. Relation between tumour necrosis factor polymorphism TNFalpha-308 and risk of asthma. Eur J Hum Genet 2002; 10:82-85.

64. Saleh M, Jonas NK, Wiegmans A, Stylli SS. The treatment of established intracranial tumors by in situ retroviral IFN-gamma transfer. Gene Ther 2000; 7:1715-1724.

65. Saleh M, Wiegmans A, Malone Q, Stylli SS, Kaye AH. Effect of in situ retroviral interleukin4 transfer on established intracranial tumors. J Natl Cancer Inst 1999; 91:438-445. 
66. Nagel GA, Piessens WF, Stilmant MM. Lejeune F Evidence for tumor-specific immunity in human malignant melanoma. Eur J Cancer 1971; 7:41-47.

67. Darnell RB, DeAngelis LM. Regression of small-cell lung carcinoma in patients with paraneoplastic neuronal antibodies. Lancet 1993; 341:21-22.

68. Speiser DE, Miranda R, Zakarian A, et al. Self antigens expressed by solid tumors. Do not efficiently stimulate naive or activated T cells: implications for immunotherapy. J Exp Med 1997; 186:645-653.

69. Marincola FM, Wang E, Herlyn M, Seliger B, Ferrone S. Tumors as elusive targets of T-cellbased active immunotherapy. Trends Immunol 2003; 24:335-342.

70. Ochsenbein AF, Klenerman $P$, Karrer U, et al. Immune surveillance against a solid tumor fails because of immunological ignorance. Proc Natl Acad Sci USA 1999; 96:2233-2238.

71. Biglari A, Bataille D, Naumann U, et al. Effects of ectopic decorin in modulating intracranial glioma progression in vivo, in a rat syngeneic model. Cancer Gene Ther 2004; 11:721-732.

72. Svane IM, Soot ML, Buus S, Johnsen HE. Clinical application of dendritic cells in cancer vaccination therapy. Apmis 2003; 111:818-834.

73. Jongmans $\mathrm{W}$, van den Oudenalder $\mathrm{K}$, Tiemessen $\mathrm{DM}$, et al. Targeting of adenovirus to human renal cell carcinoma cells. Urology 2003; 62:559-565.

74. Natsume A, Tsujimura K, Mizuno M, Takahashi T, Yoshida J. IFN-beta gene therapy induces systemic antitumor immunity against malignant glioma. J Neurooncol 2000; 47:117-124.

75. Nakahara N, Pollack IF, Storkus WJ, Wakabayashi T, Yoshida J, Okada H. Effective induction of antiglioma cytotoxic $\mathrm{T}$ cells by coadministration of interferon-beta gene vector and dendritic cells. Cancer Gene Ther 2003; 10:549-558.

76. Yoshida J, Mizuno M, Nakahara N, Colosi P. Antitumor effect of an adeno-associated virus vector containing the human interferon-beta gene on experimental intracranial human glioma. Jpn J Cancer Res 2002; 93:223-228.

77. Eck SL, Alavi JB, Judy K, et al. Treatment of recurrent or progressive malignant glioma with a recombinant adenovirus expressing human interferon-beta (H5.010CMVhIFN-beta): a phase I trial. Hum Gene Ther 2001; 12:97-113.

78. Liu $\mathrm{Y}$, Ehtesham M, Samoto K, et al. In situ adenoviral interleukin 12 gene transfer confers potent and long-lasting cytotoxic immunity in glioma. Cancer Gene Ther 2002; 9:9-15.

79. Lichtor T, Glick RP. Cytokine immuno-gene therapy for treatment of brain tumors. J Neurooncol 2003; 65:247-259.

80. Lowenstein PR. Immunology of viral-vector-mediated gene transfer into the brain: an evolutionary and developmental perspective. Trends Immunol 2002; 23:23-30.

81. McMenamin PG. Distribution and phenotype of dendritic cells and resident tissue macrophages in the dura mater, leptomeninges, and choroid plexus of the rat brain as demonstrated in wholemount preparations. J Comp Neurol 1999; 405:553-562.

82. Fischer HG, Reichmann G. Brain dendritic cells and macrophages/microglia in central nervous system inflammation. J Immunol 2001; 166:2717-2726.

83. Fischer HG, Bonifas U, Reichmann G. Phenotype and functions of brain dendritic cells emerging during chronic infection of mice with Toxoplasma gondii. J Immunol 2000; $164: 4826-4834$.

84. Santambrogio L, Belyanskaya SL, Fischer FR, et al. Developmental plasticity of CNS microglia. Proc Natl Acad Sci USA 2001; 98:6295-6300.

85. Serafini B, Columba-Cabezas S, Di Rosa F, Aloisi F. Intracerebral recruitment and maturation of dendritic cells in the onset and progression of experimental autoimmune encephalomyelitis. Am J Pathol 2000; 157:1991-2002.

86. Laouar $\mathrm{Y}$, Crispe IN. Functional flexibility in $\mathrm{T}$ cells: independent regulation of CD4 $+\mathrm{T}$ cell proliferation and effector function in vivo. Immunity 2000; 13:291-301.

87. Lynch DH, Andreasen A, Maraskovsky E, Whitmore J, Miller RE, Schuh JC. Flt3 ligand induces tumor regression and antitumor immune responses in vivo. Nat Med 1997; $3: 625-631$. 
88. Schuler G, Schuler-Thurner B, Steinman RM. The use of dendritic cells in cancer immunotherapy. Curr Opin Immunol 2003; 15:138-147.

89. Ali S, King GD, Curtin JF, et al. Combined immunostimulation and conditional cytotoxic gene therapy provide long-term survival in a large glioma model. Cancer Res 2005; 65:7194-7204.

90. Ali S, Curtin JF, Zirger J, et al. Inflammatory and anti-glioma effects of an adenovirus expressing human soluble fms-like tyrosine kinase 3-lignad (hsFlt3L): treatment with hsFlt3L inhibits intracranial glioma progression. Mol Ther 2004; 10.

91. Reed JC. Apoptosis-based therapies. Nat Rev Drug Discov 2002; 1:111-121.

92. Townson $\mathrm{J}$, Naumov GN, Chambers AF. The role of apoptosis in tumor progression and metastasis. Curr Mol Med 2003; 3:631-642.

93. Shinoura N, Hamada $\mathrm{H}$. Gene therapy using an adenovirus vector for apoptosis-related genes is a highly effective therapeutic modality for killing glioma cells. Curr Gene Ther 2003; 3:147-153.

94. Naismith JH, Sprang SR. Modularity in the TNF-receptor family. Trends Biochem Sci 1998; 23:74-79.

95. Bodmer JL, Schneider P, Tschopp J. The molecular architecture of the TNF superfamily. Trends Biochem Sci 2002; 27:19-26.

96. Curtin JF, Cotter TG. Live and let die: regulatory mechanisms in Fas-mediated apoptosis. Cell Signal 2003; 15:983-992.

97. Maleniak TC, Darling JL, Lowenstein PR, Castro MG. Adenovirus-mediated expression of HSV1-TK or Fas ligand induces cell death in primary human glioma-derived cell cultures that are resistant to the chemotherapeutic agent CCNU. Cancer Gene Ther 2001; 8:589-598.

98. Morelli AE, Larregina AT, Smith-Arica J, et al. Neuronal and glial cell type-specific promoters within adenovirus recombinants restrict the expression of the apoptosis-inducing molecule Fas ligand to predetermined brain cell types, and abolish peripheral liver toxicity. J Gen Virol 1999; 80:571-583.

99. Ambar BB, Frei K, Malipiero U, et al. Treatment of experimental glioma by administration of adenoviral vectors expressing Fas ligand. Hum Gene Ther 1999; 10:1641-1648.

100. Nafe C, Cao YJ, Quinones A, Dobberstein KU, Kramm CM, Rainov NG. Expression of mutant non-cleavable Fas ligand on retrovirus packaging cells causes apoptosis of immunocompetent cells and improves prodrug activation gene therapy in a malignant glioma model. Life Sci 2003; 73:1847-1860.

101. Shinoura N, Yoshida Y, Asai A, Kirino T, Hamada H. Adenovirus-mediated transfer of p53 and Fas ligand drastically enhances apoptosis in gliomas. Cancer Gene Ther 2000; 7:732-738.

102. Naumann U, Waltereit R, Schulz JB, Weller M. Adenoviral (full-length) Apo2L/TRAIL gene transfer is an ineffective treatment strategy for malignant glioma. J Neurooncol 2003; 61:7-15.

103. Rubinchik S, Yu H, Woraratanadharm J, Voelkel-Johnson C, Norris JS, Dong JY. Enhanced apoptosis of glioma cell lines is achieved by co-delivering FasL-GFP and TRAIL with a complex Ad5 vector. Cancer Gene Ther 2003; 10:814-822.

104. Lee J, Hampl M, Albert P, Fine HA. Antitumor activity and prolonged expression from a TRAII-expressing adenoviral vector. Neoplasia 2002; 4:312-323.

105. Banerjee D, Bertino JR. Myeloprotection with drug-resistance genes. Lancet Oncol 2002; 3:154-158.

106. Cowan KH, Moscow JA, Huang H, et al. Paclitaxel chemotherapy after autologous stem-cell transplantation and engraftment of hematopoietic cells transduced with a retrovirus containing the multidrug resistance complementary DNA (MDR1) in metastatic breast cancer patients. Clin Cancer Res 1999; 5:1619-1628.

107. Flasshove M, Moritz T, Bardenheuer W, Seeber S. Hematoprotection by transfer of drugresistance genes. Acta Haematol 2003; 110:93-106.

108. Greco O, Dachs GU. Gene directed enzyme/prodrug therapy of cancer: historical appraisal and future prospectives. J Cell Physiol 2001; 187:22-36. 
109. Cobb LM, Connors TA, Elson LA, et al. 2, 4-dinitro-5-ethyleneiminobenzamide (CB 1954): a potent and selective inhibitor of the growth of the Walker carcinoma 256. Biochem Pharmacol
$1969 ; 18: 1519-1527$.

110. Connors TA, Whisson ME. Cure of mice bearing advanced plasma cell tumours with aniline mustard: the relationship between glucuronidase activity and tumour sensitivity. Nature 1966; 210:866-867.

111. Waldmann TA, White JD, Carrasquillo JA, et al. Radioimmunotherapy of interleukin-2R alpha-expressing adult T-cell leukemia with Yttrium-90-labeled anti-Tac. Blood 1995; 86:4063-4075.

112. Cairns J. The evolution of cancer research. Cancer Cells 1989; 1:1-8.

113. Huennekens FM. Tumor targeting: activation of prodrugs by enzyme-monoclonal antibody conjugates. Trends Biotechnol 1994; 12:234-239.

114. Senter PD, Wallace PM, Svensson HP, et al. Generation of cytotoxic agents by targeted enzymes. Bioconjug Chem 1993; 4:3-9.

115. Bagshawe KD. Antibody-directed enzyme prodrug therapy. Clin Pharmacokinet 1994; 27:368-376.

116. Benhar I, Padlan EA, Jung SH, Lee B, Pastan I. Rapid humanization of the Fv of monoclonal antibody $\mathrm{B} 3$ by using framework exchange of the recombinant immunotoxin B3(Fv)-PE38. Proc Natl Acad Sci USA 1994; 91:12051-12055.

117. Co MS, Queen C. Humanized antibodies for therapy. Nature 1991; 351:501-502.

118. Riechmann L, Clark M, Waldmann H, Winter G. Reshaping human antibodies for therapy. Nature 1988; 332:323-327.

119. Jain RK. Delivery of molecular medicine to solid tumors. Science 1996; 271:1079-1080.

120. Paulie S, Ehlin-Henriksson B, Mellstedt H, Koho H, Ben-Aissa H, Perlmann P. A p50 surface antigen restricted to human urinary bladder carcinomas and B lymphocytes. Cancer Immunol Immunother 1985; 20:23-28.

121. Brinkmann U, Reiter $Y$, Jung SH, Lee B, Pastan I. A recombinant immunotoxin containing a disulfide-stabilized Fv fragment. Proc Natl Acad Sci USA 1993; 90:7538-7542.

122. Reiter Y, Brinkmann U, Webber KO, Jung SH, Lee B, Pastan I. Engineering interchain disulfide bonds into conserved framework regions of Fv fragments: improved biochemical characteristics of recombinant immunotoxins containing disulfide-stabilized Fv. Protein Eng 1994; 7:697-704.

123. Reiter Y, Brinkmann U, Lee B, Pastan I. Engineering antibody Fv fragments for cancer detection and therapy: disulfide-stabilized Fv fragments. Nat Biotechnol 1996; 14:1239-1245.

124. Ward ES, Gussow D, Griffiths AD, Jones PT, Winter G. Binding activities of a repertoire of single immunoglobulin variable domains secreted from Escherichia coli. Nature 1989; 341:544-546.

125. Davies J, Riechmann L. "Camelising" human antibody fragments: NMR studies on VH domains. FEBS Lett 1994; 339:285-290.

126. Davies J, Riechmann L. Single antibody domains as small recognition units: design and in vitro antigen selection of camelized, human VH domains with improved protein stability. Protein Eng 1996; 9:531-537.

127. Aghi M, Hochberg F, Breakefield XO. Prodrug activation enzymes in cancer gene therapy. J Gene Med 2000; 2:148-164.

128. Ram Z, Culver KW, Oshiro EM, et al. Therapy of malignant brain tumors by intratumoral implantation of retroviral vector-producing cells. Nat Med 1997; 3:1354-1361.

129. Moolten FL. Tumor chemosensitivity conferred by inserted herpes thymidine kinase genes: paradigm for a prospective cancer control strategy. Cancer Res 1986; 46:5276-5281.

130. Caruso M, Panis Y, Gagandeep S, Houssin D, Salzmann J, Klatzmann D. Regression of established macroscopic liver metastases after in situ transduction of a suicide gene. Proc Natl Acad Sci USA 1993; 90:7024-7028.

131. Culver $\mathrm{KW}$, Ram Z, Wallbridge S, Ishii H, Oldfield EH, Blaese RM. In vivo gene transfer with retroviral vector-producer cells for treatment of experimental brain tumors. Science 1992; 256:1550-1552. 
132. Kuriyama S, Mitoro A, Yamazaki M, et al. Comparison of gene therapy with the herpes simplex virus thymidine kinase gene and the bacterial cytosine deaminase gene for the treatment of hepatocellular carcinoma. Scand J Gastroenterol 1999; 34:1033-1041.

133. O'Malley BW, Jr., Chen SH, Schwartz MR, Woo SL. Adenovirus-mediated gene therapy for human head and neck squamous cell cancer in a nude mouse model. Cancer Res 1995; 55:1080-1085.

134. Short MP, Choi BC, Lee JK, Malick A, Breakefield XO, Martuza RL. Gene delivery to glioma cells in rat brain by grafting of a retrovirus packaging cell line. J Neurosci Res 1990; 27:427-439.

135. Smythe WR, Hwang HC, Elshami AA, et al. Treatment of experimental human mesothelioma using adenovirus transfer of the herpes simplex thymidine kinase gene. Ann Surg 1995; 222:78-86.

136. Dewey RA, Morrissey G, Cowsill CM, et al. Chronic brain inflammation and persistent herpes simplex virus 1 thymidine kinase expression in survivors of syngeneic glioma treated by adenovirus-mediated gene therapy: implications for clinical trials. Nat Med 1999; 5:1256-1263.

137. Solly SK, Trajcevski S, Frisen C, et al. Replicative retroviral vectors for cancer gene therapy. Cancer Gene Ther 2003; 10:30-39.

138. Elion GB, Furman PA, Fyfe JA, de Miranda P, Beauchamp L, Schaeffer HJ. Selectivity of action of an antiherpetic agent, 9-(2-hydroxyethoxymethyl) guanine. Proc Natl Acad Sci USA 1977; 74:5716-5720.

139. Davidson RL, Kaufman ER, Crumpacker CS, Schnipper LE. Inhibition of herpes simplex virus transformed and nontransformed cells by acycloguanosine: mechanisms of uptake and toxicity. Virology 1981; 113:9-19.

140. Elion GB. The chemotherapeutic exploitation of virus-specified enzymes. Adv Enzyme Regul $1980 ; 18: 53-66$.

141 Mar EC, Chiou JF, Cheng YC, Huang ES. Inhibition of cellular DNA polymerase alpha and human cytomegalovirus-induced DNA polymerase by the triphosphates of 9-(2-hydroxyethoxymethyl)guanine and 9-(1,3-dihydroxy-2-propoxymethyl)guanine. J Virol 1985; 53:776-780.

142. Freeman SM, Abboud CN, Whartenby KA, et al. The "bystander effect": tumor regression when a fraction of the tumor mass is genetically modified. Cancer Res 1993; 53:5274-5283.

143. Chen CY, Chang YN, Ryan P, Linscott M, McGarrity GJ, Chiang YL. Effect of herpes simplex virus thymidine kinase expression levels on ganciclovir-mediated cytotoxicity and the "bystander effect". Hum Gene Ther 1995; 6:1467-1476.

144. Elshami AA, Saavedra A, Zhang H, et al. Gap junctions play a role in the "bystander effect" of the herpes simplex virus thymidine kinase/ganciclovir system in vitro. Gene Ther 1996; 3:85-92.

145. Dilber MS, Abedi MR, Christensson B, et al. Gap junctions promote the bystander effect of herpes simplex virus thymidine kinase in vivo. Cancer Res 1997; 57:1523-1528.

146. Mesnil M, Piccoli C, Tiraby G, Willecke K, Yamasaki H. Bystander killing of cancer cells by herpes simplex virus thymidine kinase gene is mediated by connexins. Proc Natl Acad Sci USA 1996; 93:1831-1835.

147. Touraine RL, Vahanian N, Ramsey WJ, Blaese RM. Enhancement of the herpes simplex virus thymidine kinase/ganciclovir bystander effect and its antitumor efficacy in vivo by pharmacologic manipulation of gap junctions. Hum Gene Ther 1998; 9:2385-2391.

148. Vile RG, Castleden S, Marshall J, Camplejohn R, Upton C, Chong H. Generation of an antitumour immune response in a non-immunogenic tumour: HSVtk killing in vivo stimulates a mononuclear cell infiltrate and a Th1-like profile of intratumoural cytokine expression. Int J Cancer 1997; 71:267-274.

149. Wilson KM, Stambrook PJ, Bi WL, Pavelic ZP, Pavelic L, Gluckman JL. HSV-tk gene therapy in head and neck squamous cell carcinoma. Enhancement by the local and distant bystander effect. Arch Otolaryngol Head Neck Surg 1996; 122:746-749. 
150. Bi W, Kim YG, Feliciano ES, et al. An HSVtk-mediated local and distant antitumor bystander effect in tumors of head and neck origin in athymic mice. Cancer Gene Ther 1997; 4:246-252.

151. Dilber MS, Abedi MR, Bjorkstrand B, et al. Suicide gene therapy for plasma cell tumors. Blood 1996; 88:2192-2200.

152. Klatzmann D, Valery CA, Bensimon G, et al. A phase I/I study of herpes simplex virus type 1 thymidine kinase "suicide" gene therapy for recurrent glioblastoma. Study Group on Gene Therapy for Glioblastoma. Hum Gene Ther 1998; 9:2595-2604.

153. Shand N, Weber F, Mariani L, et al. A phase 1-2 clinical trial of gene therapy for recurrent glioblastoma multiforme by tumor transduction with the herpes simplex thymidine kinase gene followed by ganciclovir. GLI328 European-Canadian Study Group. Hum Gene Ther 1999; 10:2325-2335.

154. Moolten FL. Drug sensitivity ("suicide") genes for selective cancer chemotherapy. Cancer Gene Ther 1994; 1:279-287.

155. Yazawa K, Fisher WE, Brunicardi FC. Current progress in suicide gene therapy for cancer. World J Surg 2002; 26:783-789.

156. Domin BA, Mahony WB, Zimmerman TP. Transport of 5-fluorouracil and uracil into human erythrocytes. Biochem Pharmacol 1993; 46:503-510.

157. Huber BE, Austin EA, Richards CA, Davis ST, Good SS. Metabolism of 5-FC to 5 -fluorouracil in human colorectal tumor cells transduced with the cytosine deaminase gene: significant antitumor effects when only a small percentage of tumor cells express cytosine deaminase. Proc Natl Acad Sci USA 1994; 91:8302-8306.

158. Trinh QT, Austin EA, Murray DM, Knick VC, Huber BE. Enzyme/prodrug gene therapy: comparison of cytosine deaminase/5-fluorocytosine versus thymidine kinase/ganciclovir enzyme/prodrug systems in a human colorectal carcinoma cell line. Cancer Res 1995; 55:4808-4812.

159. Pierrefite-Carle V, Baque P, Gavelli A, et al. Cytosine deaminase/5-fluorocytosine-based vaccination against liver tumors: evidence of distant bystander effect. J Natl Cancer Inst 1999; 91:2014-2019.

160. Kievit E, Bershad E, Ng E, et al. Superiority of yeast over bacterial cytosine deaminase for enzyme/prodrug gene therapy in colon cancer xenografts. Cancer Res 1999; 59:1417-1421.

161. Hamstra DA, Rice DJ, Fahmy S, Ross BD, Rehemtulla A. Enzyme/prodrug therapy for head and neck cancer using a catalytically superior cytosine deaminase. Hum Gene Ther 1999; 10:1993-2003.

162. Martin J, Stribbling SM, Poon GK, et al. Antibody-directed enzyme prodrug therapy: pharmacokinetics and plasma levels of prodrug and drug in a phase I clinical trial. Cancer Chemother Pharmacol 1997; 40:189-201.

163. Napier MP, Sharma SK, Springer CJ, et al. Antibody-directed enzyme prodrug therapy: efficacy and mechanism of action in colorectal carcinoma. Clin Cancer Res 2000; 6:765-772.

164. Crystal RG, Hirschowitz E, Lieberman M, et al. Phase I study of direct administration of a replication deficient adenovirus vector containing the $\mathrm{E}$. coli cytosine deaminase gene to metastatic colon carcinoma of the liver in association with the oral administration of the prodrug 5-fluorocytosine. Hum Gene Ther 1997; 8:985-1001.

165. Springer CJ, Antoniw P, Bagshawe KD, Searle F, Bisset GM, Jarman M. Novel prodrugs which are activated to cytotoxic alkylating agents by carboxypeptidase G2. J Med Chem 1990; 33:677-681.

166. Springer CJ, Niculescu-Duvaz I. Prodrug-activating systems in suicide gene therapy. J Clin Invest 2000; 105:1161-1167.

167. Stribbling SM, Friedlos F, Martin J, et al. Regressions of established breast carcinoma xenografts by carboxypeptidase G2 suicide gene therapy and the prodrug CMDA are due to a bystander effect. Hum Gene Ther 2000; 11:285-292.

168. Marais R, Spooner RA, Light Y, Martin J, Springer CJ. Gene-directed enzyme prodrug therapy with a mustard prodrug/carboxypeptidase G2 combination. Cancer Res 1996; 56:4735-4742. 
169. Cowen RL, Williams JC, Emery S, et al. Adenovirus vector-mediated delivery of the prodrugconverting enzyme carboxypeptidase G2 in a secreted or GPI-anchored form: High-level expression of this active conditional cytotoxic enzyme at the plasma membrane. Cancer Gene Ther 2002; 9:897-907.

170. Debinski W, Gibo DM. Molecular expression analysis of restrictive receptor for interleukin 13, a brain tumor-associated cancer/testis antigen. Mol Med 2000; 6:440-449.

171. Debinski W, Gibo DM, Hulet SW, Connor JR, Gillespie GY. Receptor for interleukin 13 is a marker and therapeutic target for human high-grade gliomas. Clin Cancer Res 1999; 5:985-990.

172. Li C, Hall WA, Jin N, Todhunter DA, Panoskaltsis-Mortari A, Vallera DA. Targeting glioblastoma multiforme with an IL-13/diphtheria toxin fusion protein in vitro and in vivo in nude mice. Protein Eng 2002; 15:419-427.

173. Todhunter DA, Hall WA, Rustamzadeh E, Shu Y, Doumbia SO, Vallera DA. A bispecific immunotoxin (DTAT13) targeting human IL-13 receptor (IL-13R) and urokinase-type plasminogen activator receptor (UPAR) in a mouse xenograft model. Protein Eng Des Sel
2004; 17:157-164.

174. Debinski W, Obiri NI, Powers SK, Pastan I, Puri RK. Human glioma cells overexpress receptors for interleukin 13 and are extremely sensitive to a novel chimeric protein composed of interleukin 13 and pseudomonas exotoxin. Clin Cancer Res 1995; 1:1253-1258.

175. Mori T, Abe T, Wakabayashi $Y$, et al. Up-regulation of urokinase-type plasminogen activator and its receptor correlates with enhanced invasion activity of human glioma cells mediated by transforming growth factor-alpha or basic fibroblast growth factor. J Neurooncol 2000; 46:115-123.

176. Liu TF, Hall PD, Cohen KA, et al. Interstitial diphtheria toxin-epidermal growth factor fusion protein therapy produces regressions of subcutaneous human glioblastoma multiforme tumors in athymic nude mice. Clin Cancer Res 2005; 11:329-334.

177. Phillips PC, Levow C, Catterall M, Colvin OM, Pastan I, Brem H. Transforming growth factor-alpha-Pseudomonas exotoxin fusion protein (TGF-alpha-PE38) treatment of subcutaneous and intracranial human glioma and medulloblastoma xenografts in athymic mice. Cancer Res 1994; 54:1008-1015.

178. Debinski W, Obiri NI, Pastan I, Puri RK. A novel chimeric protein composed of interleukin 13 and Pseudomonas exotoxin is highly cytotoxic to human carcinoma cells expressing receptors for interleukin 13 and interleukin 4. J Biol Chem 1995; 270:16775-16780.

179. Laske DW, Youle RJ, Oldfield EH. Tumor regression with regional distribution of the targeted toxin TF-CRM107 in patients with malignant brain tumors. Nat Med 1997; 3:1362-1368.

180. Liu TF, Willingham MC, Tatter SB, et al. Diphtheria toxin-epidermal growth factor fusion protein and Pseudomonas exotoxin-interleukin 13 fusion protein exert synergistic toxicity against human glioblastoma multiforme cells. Bioconjug Chem 2003; 14:1107-1114.

181. Husain SR, Joshi BH, Puri RK. Interleukin-13 receptor as a unique target for antiglioblastoma therapy. Int J Cancer 2001; 92:168-175.

182. Kawakami K, Kawakami M, Kioi M, Husain SR, Puri RK. Distribution kinetics of targeted cytotoxin in glioma by bolus or convection-enhanced delivery in a murine model. J Neurosurg 2004; 101:1004-1011.

183. Debinski W, Gibo DM, Obiri NI, Kealiher A, Puri RK. Novel anti-brain tumor cytotoxins specific for cancer cells. Nat Biotechnol 1998; 16:449-453.

184. Madhankumar AB, Mintz A, Debinski W. Interleukin 13 mutants of enhanced avidity toward the glioma-associated receptor, IL13Ralpha2. Neoplasia 2004; 6:15-22.

185. Debinski W, Gibo DM, Puri RK. Novel way to increase targeting specificity to a human glioblastoma-associated receptor for interleukin 13. Int J Cancer 1998; 76:547-551.

186. Obiri NI, Debinski W, Leonard WJ, Puri RK. Receptor for interleukin 13. Interaction with interleukin 4 by a mechanism that does not involve the common gamma chain shared by receptors for interleukins 2, 4, 7, 9, and 15. J Biol Chem 1995; 270:8797-8804. 
187. Cicuttini FM, Hurley SF, Forbes A, et al. Association of adult glioma with medical conditions, family and reproductive history. Int J Cancer 1997; 71:203-207.

188. Obiri NI, Leland P, Murata T, Debinski W, Puri RK. The IL-13 receptor structure differs on various cell types and may share more than one component with IL-4 receptor. J Immunol $1997 ; 158: 756-764$.

189. Maini A, Hillman G, Haas GP, et al. Interleukin-13 receptors on human prostate carcinoma cell lines represent a novel target for a chimeric protein composed of IL-13 and a mutated form of Pseudomonas exotoxin. J Urol 1997; 158:948-953.

190. Kornmann M, Kleeff J, Debinski W, Korc M. Pancreatic cancer cells express interleukin-13 and -4 receptors, and their growth is inhibited by Pseudomonas exotoxin coupled to interleukin-13 and -4. Anticancer Res 1999; 19:125-131.

191. Castro MG, Cowen R, Smith-Arica J, et al. Gene therapy strategies for intracranial tumours: glioma and pituitary adenomas. Histol Histopathol 2000; 15:1233-1252.

192. Kleihues $\mathrm{P}$, Zulch KJ, Matsumoto S, Radke U. Morphology of malignant gliomas induced in rabbits by systemic application of N-methyl-N-nitrosourea. Z Neurol 1970; 198:65-78.

193. Grossi-Paoletti E, Paoletti P, Schiffer D, Fabiani A. Experimental brain tumours induced in rats by nitrosourea derivatives. II. Morphological aspects of nitrosoethylurea tumours obtained by transplacental induction. J Neurol Sci 1970; 11:573-581.

194. Barker M, Hoshino T, Gurcay O, et al. Development of an animal brain tumor model and its response to therapy with 1,3-bis(2-chloroethyl)-1-nitrosourea. Cancer Res 1973; 33:976-986.

195. Barth RF. Rat brain tumor models in experimental neuro-oncology: the 9L, C6, T9, F98, RG2 (D74), RT-2 and CNS-1 gliomas. J Neurooncol 1998; 36:91-102.

196. Boviatsis EJ, Park JS, Sena-Esteves M, et al. Long-term survival of rats harboring brain neoplasms treated with ganciclovir and a herpes simplex virus vector that retains an intact thymidine kinase gene. Cancer Res 1994; 54:5745-5751.

197. Barba D, Hardin J, Sadelain M, Gage FH. Development of anti-tumor immunity following thymidine kinase-mediated killing of experimental brain tumors. Proc Natl Acad Sci USA 1994; 91:4348-4352.

198. Tapscott SJ, Miller AD, Olson JM, Berger MS, Groudine M, Spence AM. Gene therapy of rat 9L gliosarcoma tumors by transduction with selectable genes does not require drug selection. Proc Natl Acad Sci USA 1994; 91:8185-8189.

199. Kruse CA, Molleston MC, Parks EP, Schiltz PM, Kleinschmidt-DeMasters BK, Hickey WF. A rat glioma model, CNS-1, with invasive characteristics similar to those of human gliomas: a comparison to 9L gliosarcoma. J Neurooncol 1994; 22:191-200.

200. Tzeng JJ, Barth RF, Orosz CG, James SM. Phenotype and functional activity of tumorinfiltrating lymphocytes isolated from immunogenic and nonimmunogenic rat brain tumors. Cancer Res 1991; 51:2373-2378.

201. Albright L, Madigan JC, Gaston MR, Houchens DP. Therapy in an intracerebral murine glioma model, using Bacillus Calmette-Guerin, neuraminidase-treated tumor cells, and 1-(2-chloroethyl)-3-cyclohexyl-1-nitrosourea. Cancer Res 1975; 35:658-665.

202. Akbasak A, Oldfield EH, Saris SC. Expression and modulation of major histocompatibility antigens on murine primary brain tumor in vitro. J Neurosurg 1991; 75:922-929.

203. Weiner NE, Pyles RB, Chalk CL, et al. A syngeneic mouse glioma model for study of glioblastoma therapy. J Neuropathol Exp Neurol 1999; 58:54-60.

204. Weissenberger J, Steinbach JP, Malin G, Spada S, Rulicke T, Aguzzi A. Development and malignant progression of astrocytomas in GFAP-v-src transgenic mice. Oncogene 1997; 14:2005-2013.

205. Ding H, Roncari L, Shannon P, et al. Astrocyte-specific expression of activated p21-ras results in malignant astrocytoma formation in a transgenic mouse model of human gliomas. Cancer Res 2001; 61:3826-3836.

206. Begemann M, Fuller GN, Holland EC. Genetic modeling of glioma formation in mice. Brain Pathol 2002; 12:117-132. 
207. Reilly KM, Loisel DA, Bronson RT, McLaughlin ME. Nf1;Trp53 mutant mice develop glioblastoma with evidence of strain-specific effects. Nat Genet 2000; 26:109-113.

208. Dai C, Celestino JC, Okada Y, Louis DN, Fuller GN, Holland EC. PDGF autocrine stimulation dedifferentiates cultured astrocytes and induces oligodendrogliomas and oligoastrocytomas from neural progenitors and astrocytes in vivo. Genes Dev 2001; 15:1913-1925.

209. Germano IM, Fable J, Gultekin SH, Silvers A. Adenovirus/herpes simplex-thymidine kinase/ganciclovir complex: preliminary results of a phase I trial in patients with recurrent malignant gliomas. J Neurooncol 2003; 65:279-289.

210. Prados MD, McDermott M, Chang SM, et al. Treatment of progressive or recurrent glioblastoma multiforme in adults with herpes simplex virus thymidine kinase gene vectorproducer cells followed by intravenous ganciclovir administration: a phase I/II multiinstitutional trial. J Neurooncol 2003; 65:269-278.

211. Smitt PS, Driesse M, Wolbers J, Kros M, Avezaat C. Treatment of relapsed malignant glioma with an adenoviral vector containing the herpes simplex thymidine kinase gene followed by ganciclovir. Mol Ther 2003; 7:851-858.

212. Sandmair AM, Loimas S, Puranen P, et al. Thymidine kinase gene therapy for human malignant glioma, using replication-deficient retroviruses or adenoviruses. Hum Gene Ther 2000; 11:2197-2205.

213. Trask TW, Trask RP, Aguilar-Cordova E, et al. Phase I study of adenoviral delivery of the HSV-tk gene and ganciclovir administration in patients with current malignant brain tumors. Mol Ther 2000; 1:195-203.

214. Immonen A, Vapalahti $M$, Tyynela $\mathrm{K}$, et al. AdvHSV-tk gene therapy with intravenous ganciclovir improves survival in human malignant glioma: a randomised, controlled study. Mol Ther 2004; 10:967-972.

215. Madara J, Krewet JA, Shah M. Heat shock protein 72 expression allows permissive replication of oncolytic adenovirus dl1520 (ONYX-015) in rat glioblastoma cells. Mol Cancer 2005; 4:12.

216. O'Shea CC, Johnson L, Bagus B, et al. Late viral RNA export, rather than p53 inactivation, determines ONYX-015 tumor selectivity. Cancer Cell 2004; 6:611-623.

217. Chiocca EA, Abbed KM, Tatter S, et al. A phase I open-label, dose-escalation, multiinstitutional trial of injection with an E1B-Attenuated adenovirus, ONYX-015, into the peritumoral region of recurrent malignant gliomas, in the adjuvant setting. Mol Ther 2004; 10:958-966.

218. Markert JM, Medlock MD, Rabkin SD, et al. Conditionally replicating herpes simplex virus mutant, G207 for the treatment of malignant glioma: results of a phase I trial. Gene Ther 2000; 7:867-874.

219. Rampling R, Cruickshank G, Papanastassiou V, et al. Toxicity evaluation of replicationcompetent herpes simplex virus (ICP 34.5 null mutant 1716) in patients with recurrent malignant glioma. Gene Ther 2000; 7:859-866.

220. Papanastassiou V, Rampling R, Fraser M, et al. The potential for efficacy of the modified (ICP 34.5(-)) herpes simplex virus HSV1716 following intratumoural injection into human malignant glioma: a proof of principle study. Gene Ther 2002; 9:398-406.

221. Harland J, Papanastassiou V, Brown SM. HSV1716 persistence in primary human glioma cells in vitro. Gene Ther 2002; 9:1194-1198.

222. Harrow S, Papanastassiou V, Harland J, et al. HSV1716 injection into the brain adjacent to tumour following surgical resection of high-grade glioma: safety data and long-term survival. Gene Ther 2004; 11:1648-1658.

223. Schneider T, Gerhards R, Kirches E, Firsching R. Preliminary results of active specific immunization with modified tumor cell vaccine in glioblastoma multiforme. $\mathrm{J}$ Neurooncol $2001 ; 53: 39-46$.

224. Steiner HH, Bonsanto MM, Beckhove $P$, et al. Antitumor vaccination of patients with glioblastoma multiforme: a pilot study to assess feasibility, safety, and clinical benefit. J Clin Oncol 2004; 22:4272-4281. 
225. Hall WA, Rustamzadeh E, Asher AL. Convection-enhanced delivery in clinical trials. Neurosurg Focus 2003; 14:e2.

226. Weber F, Asher A, Bucholz R, et al. Safety, tolerability, and tumor response of ILAPseudomonas exotoxin (NBI-3001) in patients with recurrent malignant glioma. J Neurooncol 2003; 64:125-137.

227. Rand RW, Kreitman RJ, Patronas N, Varricchio F, Pastan I, Puri RK. Intratumoral administration of recombinant circularly permuted interleukin-4-Pseudomonas exotoxin in patients with high-grade glioma. Clin Cancer Res 2000; 6:2157-2165.

228. Weaver M, Laske DW. Transferrin receptor ligand-targeted toxin conjugate (Tf-CRM107) for therapy of malignant gliomas. J Neurooncol 2003; 65:3-13.

229. Sampson JH, Akabani G, Archer GE, et al. Progress report of a Phase I study of the intracerebral microinfusion of a recombinant chimeric protein composed of transforming growth factor (TGF)-alpha and a mutated form of the Pseudomonas exotoxin termed PE-38 (TP-38) for the treatment of malignant brain tumors. J Neurooncol 2003; 65:27-35. 